\title{
FUGGIRE LA GIUSTIZIA, GIUSTIZIARE I FUGGITIVI: OSSERVAZIONI PRELIMINARI SULL'EVASIONE DAL CARCERE NEL DIRITTO COMUNE
}

\section{FLEEING JUSTICE, CHASING ESCAPERS: PRELIMINARY OBSERVATIONS ON PRISON ESCAPE IN THE IUS COMMUNE}

\section{Giacomo Alberto Donati}

Università degli Studi di Pavia

\begin{abstract}
English: The origin of prison punishment has recently been subjected to renewed scrutiny: on one hand, Michel Foucault and the historiography which followed his teachings asserted that the only proper way of visualizing the historical origin of prison punishment is to point to the Enligthment Age, in which the right economic and cultural conditions were sufficiently present to allow its springing; on the other, Guy Geltner has convincingly demonstrated, through documentary and archival sources, that 13th century Italy knew not only various forms of prison punishment but also that the local municipal administrations managed to establish authentic (if elementary) forms of prison's organization.

In regarding the phenomenon of prison escape, the first historiography, coherently, did not take into account any form of Medieval or Early Modern jail breaking (even if the escapes were famous and well known as the one of Hugo Grotius, which the paper recounts in the first paragraph); the second historiography contemplated the possibility of mates breaching bonds and taking their chance to conquer freedom but concluded that this was a rare occurrence. Neither of these historiographies, after all, analysed what the law prescribed on this subject.

This paper aims to fill this gap: the second paragraph is thus devoted first to illustrate the content of some Roman law's prescription on the subject, where the most probable punishment for the prisoners who committed jail breaking was of capital sort (which in Roman law didn't mean necessarily death but inevitably involved some loss of liberty, properties or - in the gravest case - life or limb).

Then, it proceeds to expound the different interpretations that the 14th century's jurists produced on the topic: beginning from the only known treaty ever written in the Middle Age on the subject of prison and walking throughout the various readings offered on the subject by law professors, attorneys and judges, the paper shows that, albeit capital punishment still persisted during the course of the entire century, the teachings of the jurists tried to distinguish between prison escapes that deserved death (such as was the case when the prisoners harmed the guards in order to obtain their freedom), prison escapes that made the fugitive fictitiously confess (being the technique used here by lawyers a true fictio iuris) the crime for which they were in the first place incarcerated and
\end{abstract}

* Italian Review of Legal History, 7 (2021), n. 3, pagg. 47-107

* https://riviste.unimi.it/index.php/irlh/index

* ISSN 2464-8914 - DOI 10.54103/2464-8914/16885. Articolo pubblicato sotto Licenza CC-BY. 
prison escapes that were punished by judges using their vast arsenal of arbitrary powers (power that, when used properly, did not extend, ever, to death).

Things, the paper continues to show, were not so much different in Church's court, where the repression of heresy demanded the direct intervention of the Pope: the subsequent reading of the orders produce by the papacy by canonists confirms that provisions similar to the ones adopted into secular courts were also well known in ecclesiastical ones.

It was not until the beginning of the Early Modern Age that some light began to shine over this bleak picture: through the systematization of the criminal law conducted by the first manuals (practicae), which specifically addressed this not yet independent branch of the legal order, the crime of prison escape was placed into a more homogeneous perspective. Usually written by jurists who daily practiced law in courts as judges or lawyers, these texts report the certainly not desirable (and sometimes inhumane) conditions in which mates were confined but also about the evolution through which the crime of prison escape was inexorably attracted into the orbit of judicial discretion (arbitrium) and, ultimately, far away from the death penalty which Roman law originally fulminated.

The last part of the central paragraph is then devoted to the exam of some consilia (allegations written by lawyers on behalf of clients who attempted or managed to escape or by consultants called to advise the court) and decisiones (decisions adopted by supreme sovereign courts), which contribute to add more details to the analysis and to confirm the impression that the punishment for jail breaking was, at least in the Early Modern Age, not any more considered to be worth of capital punishment.

The last considerations of the entire essay are, finally, inspired by the pages of the Dutch law professor Anton Mattheus II (1601-1654), who thoroughly confirm the evolution trend in the punishing of jail breaking and cite the very case of the prison escape of his countrymen Hugo Grotius, with which the essay begins.

Keywords: Prison Escape; Criminal Legal History; Utrumque ius; Hugo Grotius; Cultural Legal History

Abstract Italiano: Il tema dell'evasione dal carcere risulta essere tra quelli attorno ai quali, in epoca di utrumque ius, si appuntò l'attenzione tanto della dottrina civilistica quanto di quella canonistica (oltre che di grandi nomi della cultura occidentale come Tommaso d'Aquino). Attraverso il ricorso a diversi generi letterari (commentaria, tractatus, consilia, decisiones, practicae), il presente contributo si prefigge il compito di illustrare alcune delle conclusioni più rilevanti sul tema, prendendo specialmente in considerazione quel torno di tempo dato dal tramontare del Medioevo nella prima Modernità.

Parole chiave: Evasione dal carcere; Storia del diritto penale; Utrumque ius; Hugo Grotius; Storia della cultura giuridica

Sommario: 1. Fuga da Loevestein: I'evasione di Hugo Grotius (1621). - 2. Carcerum effractores: la repressione dell'evasione nel diritto comune classico. - 2.1. I dubbi della dottrina trecentesca: tra poena capitis, ficta confessio ed arbitrium. - 2.2. Tra inquisizione ed actus licitus: il contributo del diritto canonico. - 2.3. La viva voce della prassi penalistica: la prima età moderna e la vittoria dell'arbitrium iudicis. -2.4 . Alcuni casi concreti: consilia e decisiones. - 3. Conclusioni. 


\section{Fuga da Loevestein: l'evasione di Hugo Grotius (1621)}

Nel corso dei primi decenni del Seicento, le neonate Province Unite assistettero ad una disputa teologica dalle gravide conseguenze per la storia del diritto: da una parte stavano i calvinisti più ortodossi guidati da Franciscus Gomarus (François Gomaer), fautori di una stretta aderenza alla dottrina della predestinazione, propugnatori della superiorità della comunità ecclesiale sull'autorità civile e, soprattutto, favorevoli all'istituzione di una chiesa di Stato; dall'altra parte, invece, i seguaci di Jacobus Arminius (Jacob Hermanszoon), i quali si opponevano ai Gomaristi non solo muovendo da differenti posizioni teologiche ma predicando altresì un'ariosa concezione di tolleranza religiosa. La disfida, sino a quel momento contenuta entro un bacino strettamente dottrinario, tracimò oltre gli argini della teologia, passando al corso limaccioso della politica, allorquando i Gomaristi domandarono l'accentramento di maggiori poteri in capo agli Stati Generali delle Province Unite, unitamente ad una ripresa delle ostilità con la Spagna cattolica; gli Arminiani, come prevedibile, risposero con argomentazioni diametralmente opposte, invocando una più decentrata suddivisione di competenze a favore delle singole Province, assieme ad una pace duratura con la corona iberica.

Il sinodo di $\operatorname{Dort}^{1}$ (1618-1619) pose fine alla diatriba mettendo al bando le tesi arminiane e provocando la rovina delle fortune politiche di tutti i pubblici ufficiali professanti tale credo: tra questi, il più celebre fu senz'altro Hugo Grotius (Huig de Groot), all'epoca Pensionario di Rotterdam (1613-1619) e già autore del celebre Mare liberum (1609).

Subito tratto in arresto assieme ad altri notabili di fede arminiana, Grotius venne processato (innanzi ad una corte della quale, anche in anni seguenti, il giurista non cessò mai di protestare la parzialità) e condannato al carcere a vita, da scontarsi presso il castello di Loevenstein.

Le condizioni di prigionia furono in un primo momento piuttosto rigide ma si fecero, col passare dei mesi, vieppiù lasse: alla moglie di Grotius, Maria, venne infatti concesso di abitare assieme al marito entro le mura del castello; a lui, di scambiare lettere con amici e di ricevere da questi libri in prestito. La voluminosa cassa con la quale questi tomi venivano recapitati a Grotius - che li adoperava in lunghe ore di studio - veniva cionondimeno attentamente ispezionata dalle guardie: col tempo, però, la più accorta Maria notò come la sorveglianza divenisse sempre più lasca e divisò quindi un ingegnoso piano d'evasione, ad esclusivo vantaggio del marito. Occultatosi nella medesima cassa che serviva a trasmettergli i libri, Grotius riuscì a riconquistare la propria libertà il 22 marzo 1621, riparando in Francia (ove avrebbe composto e licenziato per le stampe i celeberrimi De veritate religionis christianae e De iure belli ac pacis) e riuscendo in seguito a ricongiungersi con la moglie ed i figli (contro i quali le autorità olandesi non vollero in alcun modo accanirsi), seppur per sempre in esilio dalla sua terra natia e piagato

\footnotetext{
${ }^{1}$ I cui atti son editi criticamente in Sinnema, Moser, Selderhuis, 2015.
} 
da gravose ristrettezze economiche ${ }^{2}$.

Il celebre caso dell'evasione di Hugo Grotius, testé rapidamente riassunto, è parso, nella sua epitomatica esemplarità, ben compendiare alcuni tra gli aspetti che più di recente hanno stimolato la riflessione storiografica in merito al rapporto tra sistemi di giustizia penale e carcerazione: sono due, però, gli elementi sui quali si vuole qui far indugiare maggiormente l'attenzione del lettore, ossia la natura della pena inflitta al Grotius a seguito del bando di Dort e le conseguenze giuridiche della sua evasione dal carcere di Loevestein.

Per ciò che concerne il primo aspetto - il quale qui, lo si sottolinea, non si avrà occasione per approfondire, rimandando piuttosto agli studi che verranno subito citati -, non può non rievocarsi fugacemente quell'ampio ed articolato dibattito (al quale non è mancato l'apporto offerto dalla storiografia del diritto ${ }^{3}$ ) concernente l'originaria valenza punitiva del carcere: da una parte, infatti, è dato rinvenire la posizione che già fu di Michel Foucault ${ }^{4}$, dei suoi predecessori Rusche e Kirchheimer ${ }^{5}$ e del di loro ampio e variegato seguito ${ }^{6}$, secondo la quale non è possibile discorrere propriamente di pena detentiva (e tantomeno di condanna al carcere perpetuo) se non con l'avvento dei Lumi; dall'altra, invece, la posizione di Guy Geltner ${ }^{8}$ e della storiografia medievistica ${ }^{9}$, a parere della quale già l'epoca di mezzo, perlomeno a partire dal XIII secolo, conobbe forme di imprigionamento afflittivo vere e proprie, non limitate, quindi, alla sola finalità custodiale.

Anche sul versante dell'evasione - ovverosia il tema al quale è consacrato il presente contributo -, del tutto coerentemente con le premesse testé succintamente riportate ${ }^{10}$, è sempre il fronte geltneriano quello che si presta maggiormente

\footnotetext{
${ }^{2}$ Le vicende sino a qui narrate concernenti la vita, le opere ed il contesto storico della prigionia del grande olandese si sono basate sulle ricostruzioni proposte (tra le moltissime disponibili) in Nellen, 2015; Mühlegger 2007; Jeffery, 2006; Heering, 2004.

${ }^{3}$ Per la quale si rimanda qui, perlomeno, ai contributi di Donati, 2020a; Nobile Mattei, 2019; Passarella, 2018; Garlati, 2017; Cavina, 2013a, pp. 115-122; Sbriccoli, 2009a.

${ }^{4}$ II riferimento è qui, naturalmente, a Foucault, 1975.

${ }^{5}$ Rusche, Kirchheimer, 1968.

${ }^{6}$ All'interno del quale si contano, nell'amplissima bibliografia, gli studi di Melossi, Pavarini, 2018; Travaglia Cicirello, 2018; Antonielli, 2006; Petit, Faugeron, Pierre, 2002; Gallo, Ruggiero, 1983; Paglia, 1980; Neppi Modona, 1973.

${ }^{7}$ In una perspicua intervista ora consultabile in Foucault, 2011, p. 76, il collegiale di Francia faceva notare, a chi gli opponeva come nel Medioevo già esistessero prigioni e istituti di reclusione, che "vi si rinchiudevano le persone solo fino al momento del giudizio, fino al pagamento del riscatto o fino all'esecuzione».

${ }^{8}$ Geltner, 2012.

${ }^{9}$ Limitando qui il rimando ai soli, principali studi germinati a seguito delle proposte del Geltner, si rammentano perlomeno: Ludwig Jansen, 2018; Gazzini, 2017; Bretschneider, Claustre, Heullant-Donat, Lusset, 2017; Bretschneider, Claustre, Heullant-Donat, Lusset, 2015; Rossi M. C., 2013; Claustre, Heullant-Donat, Lusset, 2011.

${ }^{10}$ Segue, consequenzialmente, l'impostazione foucaultiana il recente Pedrini, 2018.
} 
a fornire le considerazioni più rilevanti per il presente intervento: espressamente presa in considerazione tra le cinque modalità «per lasciare una prigione medievale ${ }^{11}$, la fuga dal carcere appare, cionondimeno, quantitativamente poco rilevante nella ricostruzione del Geltner.

\begin{abstract}
Il tasso di evasioni relativamente scarso era in effetti legato alle opportunità che i detenuti avevano all'esterno. II successo della fuga cominciava col lasciare la prigione, ma il problema immediatamente successivo era appunto come sopravvivere fuori di quelle mura. L'anonimato delle moderne metropoli e la disponibilità di trasporti non erano certo caratteristiche dei centri urbani medievali. Un detenuto evaso doveva nascondersi - compito impossibile date le dimensioni delle città medievali - oppure fuggire; ma questa era una scelta impraticabile per coloro che non avessero mezzi considerevoli. La fuga implicava un mutamento significativo della vita di un individuo, e pochi volevano affrontare tale sacrificio, dati soprattutto i pericoli che comportava ${ }^{12}$.
\end{abstract}

Sebbene l'autore ammetta, immediatamente dopo, come le cose potessero differire nel caso di prigionieri che «provenivano dai dintorni della città o che risiedevano in luoghi e territori ancora più lontani» ${ }^{13}$, è cionondimeno da segnalare l'assenza, nel luogo citato, di qualsivoglia considerazione sulle conclusioni formulate dalla dottrina di diritto comune a proposito dell'evasione ${ }^{14}$.

Proprio alla luce di tale mancanza, il presente contributo si prefigge il compito di sondare, per vie necessariamente preliminari, alcune delle conclusioni formulate dalla scienza giuridica di diritto comune in tema d'evasione, prendendo in considerazione un arco temporale che, dalle soglie del Trecento, conduca sino alla prima età moderna, allorché la questione delle conseguenze giuridiche della fuga ${ }^{15}$ dal luogo di prigionia aveva avuto modo di affaccendare già per secoli le menti di tanti giuristi ${ }^{16}$.

\footnotetext{
${ }^{11}$ Geltner, 2012, p. 123.

12 Ivi, p. 126.

13 Ibidem.

${ }^{14}$ In ciò marcando una differenza vistosa con quanto ricostruito dall'autore in riferimento alla questione della valenza anche punitiva del carcere, ove perlomeno le considerazioni di Baldo e dell'anonimo del De carceribus son state espressamente prese in considerazione (Geltner, 2012, pp. 84-87).

${ }^{15}$ Più ampie riflessioni sulla fuga quale fenomeno giuridico in Rossi G., 2013.

${ }^{16}$ Senza con ciò voler naturalmente affermare che del tema nessuno, specialmente tra le fila degli storici del diritto, si sia mai occupato: in proposito, si possono vedere le considerazioni di Isotton, 2012.
} 


\section{Carcerum effractores: la repressione dell'evasione nel diritto comune classico}

Il punto di partenza della riflessione sulle conseguenze giuridiche dell'evasione non poteva non essere rappresentato dalla prima lex del titolo quarantasettesimo del Digesto (D. 47.18.1, l. de iis), espressamente dedicato agli «effractoribus» ${ }^{17}$ :

de iis, qui carcere effracto evaserunt, sumendum supplicium, divi fratres Aemylio Tyroni rescripserunt. Saturninus etiam probat, eos qui de carcere eruperunt, sive effractis foribus, sive conspiratione cum caeteris, qui in eadem custodia erant, capite puniendos; quod si per negligentiam custodum evaserint, levius puniendos ${ }^{18}$.

Chiarito il significato dei lemmi "eruperunt» («id est, qui fugerunt rupto carcere $»^{19}$ ) e "foribus» («id est ostiis domus, ubi erant in captivitate $\left.{ }^{20}\right)$, è pur sempre la glossa ordinaria a richiamare esplicitamente ${ }^{21} \mathrm{i}$ successivi fondamenti legislativi, ossia D. 48.3.13, I. in eos,

in eos, qui cum recepti essent in carcerem, conspiraverint, ut ruptis vinculis, et effracto carcere evadant, amplius, quam causa ex qua recepti sunt, reposcit, constituendum ${ }^{22}$ est et quamvis innocentes ex eo crimine inveniantur, propter quod impacti sunt in carcerem, tamen puniendi sunt. Eos vero, qui conspirationem eorum detexerint, relevandos ${ }^{23}$,

\section{e D. 49.16.13, I. milites agrum, § eius,}

eius fugam, qui cum sub custodia, vel in carcere esset, discesserit, in numero desertorum non computandum. Menander scripsit: quia custodiae refuga, non desertor militiae est. Eum tamen qui carcere effracto fugerit, etiam si ante non deserverit, capite puniendum, Paulus respondit ${ }^{24}$.

Una lettura complessiva dei passi testé citati restituisce all'interprete un quadro normativo dalle tinte piuttosto fosche: agli evasi, infatti, ricondotti nelle mani della giustizia, va riservata una punizione dura, di natura capitale. Tale severa pena ${ }^{25}$, del resto, andrà irrogata anche nel caso, successivamente, questi vengano trovati innocenti del reato per il quale erano stati originariamente detenuti,

\footnotetext{
${ }^{17}$ Digestum Novum, 1558, fol. 959.

18 Ibidem.

19 Ibidem.

${ }^{20}$ Ibidem.

${ }^{21}$ Si veda gl. capite, ad D. 47.18.1, I. de iis (Digestum Novum, 1558, fol. 959).

22 La glossa ordinaria (Digestum Novum, 1568, fol. 984) interviene a correggere questo lemma con "custodiendum est».

${ }^{23}$ Digestum Novum, 1558, fol. 984.

24 Digestum Novum, 1558, foll. 1165-1166.

${ }^{25}$ Sulla funzione della pena capitale nel diritto comune hanno recentemente riflettuto Pifferi, 2019; Mancuso, 2019; Nobile Mattei, 2019; Alessi, 2013; Cavina, $2013 a$.
} 
non lasciando quindi trasparire alcun dubbio circa la piena configurabilità di una vera e propria fattispecie criminosa attinente la repressione di qualsiasi evenienza evasiva (e tale impressione non può che risultare confermata dall'ordinata scansione cronologica della Milites agrum, ove l'evento effrattivo è chiaramente distinto dalla successiva, conseguente punizione capitale). Esiste, cionondimeno, un'eccezione esplicita alla rigidità di tale previsione, ossia qualora la fuga sia stata favorita dal concorso negligente e colposo delle guardie; da segnalare, inoltre, la presenza di una vera e propria norma premiale, riservata ai detenuti che si facciano delatori delle cospirazioni degli altri prigionieri: a costoro, infatti, è promessa la più ampia remissione di qualsiasi pena.

2.1 I dubbi della dottrina trecentesca: tra poena capitis, ficta confessio ed arbitrium

L'impegno della dottrina trecentesca in tema d'evasione può essere illustrato a partire da quel trattato De carceribus, «per molto tempo unico lavoro monografico sull'argomento ${ }^{26}$, la cui paternità è stata attribuita ora a Bartolo, ora a Baldo, ora ancora ad altri, rimanendo, cionondimeno, sostanzialmente ignota ${ }^{27}$; al $\mathrm{ca}$ put secundum, l'anonimo così riassume la questione, gettando solo in parte una luce chiarificatrice sul tema:

nunc restat videre de poena fugientis: dico quod capite punitur, ut I.1.C.de effra.\& expi. [rectius: D. 47.18.1] et vide loannes Andreae in c.pe.de apost. [X. 5.9] super $\mathrm{gl}$. et certe sciendum est, quod ille qui fugit de carceribus videtur delictum confiteri, ut l.ad comentariensem.C.de cust.reo. [C. 9.4.4] idem nota Archidiaconus in c.ut commisso.de haer.li.6. [VI. 5.2.12] unum tamen dico quod numquam praesumitur quod reus fugiat si est spes de proximo, quod debeat relaxari [...]. Sed iuxta praedicta quaero, quid si ostium carceris erat apertum, et effugierit incarceratus numquid punietur, dico quod sic [...]. ${ }^{28}$.

Nella ricostruzione del De carceribus, il richiamo alla menzionata lex De iis (D. 47.18.1) serve dunque, anzitutto, a fondare la natura capitale delle conseguenze repressive a carico dell'evaso: I'interpretazione, del resto, si arricchisce di un ulteriore tassello allorquando l'anonimo sostiene che il fuggitivo sia paragonabile a colui che abbia confessato apertamente il proprio delitto, richiamando in proposito l'Ad commentariensem (C. 9.4.4), attraverso la quale, invero, è compiuto un notevole tentativo espansivo della portata della norma, giacché questa disposizione concerne la pena da riservare al custode delle carceri (che andrà punito con la medesima pena dell'evaso che, per incuria sua o dei suoi sottoposti, è riuscito ad evadere ${ }^{29}$ ) e non al fuggitivo. Confortato in tali conclusioni dai dicta del D'An-

\footnotetext{
${ }^{26}$ Sarti, 1980-1981, p. 96.

${ }^{27}$ Cortese, 2013, pp. 150-151; Colli, 2005, p. 39.

${ }^{28}$ De carceribus, 1584 , fol. $201 v$.

${ }^{29}$ Per il punto di C. 9.4.4, I. ad commentariensem qui preso in considerazione si veda
} 
drea e dell'Arcidiacono (dei quali si dirà al prossimo paragrafo), l'incognito autore si perita, ciononostante, di contemplare il caso di colui che semplicemente trovi le porte aperte della propria prigione e ne approfitti per riconquistare la libertà, pur senza usare alcuna violenza o astuzia. Confermando le tinte di severità che caratterizzano la trattazione, l'anonimo conclude come, anche nel caso di quest'ultima evenienza, l'evasione vada qualificata come criminosa e punita conseguentemente.

La dura presa di posizione del De carceribus, per quanto cristallina nella sua qualificazione della natura capitale del crimine d'evasione, deve cionondimeno essere collocata nel più ampio panorama della dottrina trecentesca: in proposito, Cino Sinibuldi da Pistoia ${ }^{30}$ (1270-1336), nel suo commento al libro nono del Codex, allorché tratta della testé menzionata Ad commentariensem (C. 9.4.4), fa rilevare - sciolta, preliminarmente, la questione circa la ratio della punizione da riservare al custode delle carceri che non riesca ad impedire, per sua colpa, la fuga dei detenuti alla luce del principio, di capitale importanza per la storia del diritto penale europeo ${ }^{31}$, «ut maleficia non remaneant impunita» ${ }^{32}$ - come

haec lex continet duo dicta principaliter. [...] Secundo oppono dicitur hic, quod si custodita persona fugerit, quod custos punitur eadem poena, qua incarceratus puniri debebat. Sed contra hoc, quod non possit procedere, sic opponitur: nam pone, quod ille qui fugit, tenebatur pro homicidio, et sic in dolo erat. Sed iste officialis est in culpa, et I.Cornelia de sica. non competit nisi pro dolo, ergo non videtur, quod sit eadem poena puniendus. Respondeo, verum esset, si diceremus quod hic teneretur lege Cornelia sed non punitur per Corneliam sed per legem istam capitaliter, si fugiens erat capitaliter puniendus ${ }^{33}$.

Rilevata, fugacemente, la presenza nell'argomentare di Cino di stilemi propri della tradizione scolastica ${ }^{34}$, a colpire particolarmente l'attenzione è la constatazione di come, allorché si trova ad esemplare la pena del custode su quella del fuggitivo, lo stilnovista debba rimarcare che la pena capitale toccherà in sorte al guardiano reo di culpa in vigilando solo e solamente qualora questa già fosse da riservare all'evaso, quasi come se, in effetti, non sussistesse alcuna necessità di

Codex, 1558, fol. 1400: «nam ipsum [commentariensem] volumus huiusmodi poena comsumi, qua obnoxius docebitur fuisse, qui fugerit». Un caso rilevante per la storia delle punizioni da riservare ai custodi delle carceri che si lasciassero sfuggire dalle mani $\mathrm{i}$ detenuti rimessi alle loro cure in Fugazza, 2017.

${ }^{30}$ Sul capostipite della scuola del Commento si vedano i recenti Carrai, Maffei, 2018; Ferrilli, 2016; Maffei, 2013a.

${ }^{31}$ Meccarelli, 2017; Varalda, 2016; Sbriccoli, 2009b.

${ }^{32}$ Cynus Pistoriensis, 1578, fol. 541r.

${ }^{33}$ Ivi, foll. 541r-v.

${ }^{34}$ Sulla contiguità, specie successivamente alla fioritura della scuola di Orléans, tra scienza giuridica e scienza teologica si rimanda agli studi di Lucchesi, 2018; Padoa Schioppa, 2003, pp. 149-166; Berman, 1998, pp. 153-156; Cortese, 1995, pp. 409-410. 
punire quest'ultimo con una sanzione di tale gravità. Non sembra dunque possibile rinvenire, stando perlomeno al contenuto del passo citato, alcuna adesione diretta (e nemmeno indiretta) da parte del giurista pistorese a quel severo criterio letterale ricorrendo al quale l'anonimo del De carceribus aveva fulminato la più grave sanzione a chi fuggisse dalla prigionia.

Da questo punto di vista, le parole del grande allievo di Cino, Bartolo da Sassoferrato ${ }^{35}$ (1313/1314-1357), giungono senz'altro a suffragare quelle del maestro; nemmeno la lucerna iuris, infatti, nel commento alla tredicesima lex del titolo De custodia et exhibitione reorum (D. 48.3.13, I. in eos), appare sanzionare (perlomeno esplicitamente) l'interpretazione offerta nel trattato monografico sulla carcerazione, e ciò pur richiamando apertamente, nel corso della sua stringata riflessione, la fattispecie dell'effractio carceris:

vos habuistis supra qualiter puniantur personae qui non custodierunt bene, nunc sequitur videre de personis custoditis. Et notatur hanc legem quod illi qui ruptis carceribus effugiunt, puniuntur de effractione carceris, illa poena, in qua punirentur, si vere illud maleficium commisissent, propter quod in carcere sunt missi ${ }^{36}$.

Sono perlomeno due gli elementi che (oltre alla già accennata mancanza di qualsiasi esplicito riferimento alla pena capitale) meritano qui di essere maggiormente evidenziati: anzitutto, giova sottolineare come l'interpretazione bartoliana ruoti intorno all'idea di una piena autonomia del reato d'evasione, meritevole, come del resto già adombrato nei passi anzi citati del Digesto, di una punizione specifica, distinta da qualsiasi altra fattispecie. Cionondimeno, la proposta di Bartolo si discosta, e marcatamente, dalle norme giustinianee laddove si spinge a specificare la natura della pena da infliggere all'evaso: in un'interpretazione che si accosta, per certi versi, a quella proposta nel secondo periodo del citato passo del De carceribus, il maestro sostiene che la pena più consona sia, in effetti, quella che sarebbe toccata al reo nel caso egli avesse effettivamente commesso il delitto per il quale si trovava recluso in carcere. L'utilizzo della locuzione "si vere illud maleficium commisissent», del resto, autorizza a ricomprendere, seppur solo indirettamente, l'interpretatio bartoliana nel novero delle opinioni di coloro che proponevano di comparare, attraverso una finzione giuridica ${ }^{37}$, il trattamento sanzionatorio di chi sfuggisse alla prigione con quello del reo confesso $^{38}$. Infine, può rivestire un non trascurabile rilievo il fatto che non sia dato rintracciare nelle parole di Bartolo - perlomeno in termini espliciti - la presenza

\footnotetext{
${ }^{35}$ Lepsius, 2013; Rossi, 2012a.

${ }^{36}$ Bartolus a Saxoferrato, 1590, fol. 153r.

${ }^{37}$ Sull'importanza della tecnica della fictio per la storia del diritto si vedano le pagine densissime di Thomas, 2016.

${ }^{38}$ Sul ruolo centrale della confessione nel diritto comune si rimanda perlomeno a Garlati, 2015 e Marchetti, 1994.
} 
di un'automatica e necessaria imposizione della pena capitale ${ }^{39}$, in ciò marcando una differenza sostanziale tanto con la lettera delle Pandette quanto con la lezione del De carceribus.

Se si volge, del resto, lo sguardo agli insegnamenti cattedratici e ai pareri forensi di Baldo degli Ubaldi ${ }^{40}$ (1327-1400) in tema d'evasione, sarà dato riscontrare una certa differenza tra le riflessioni del Baldo professore e le conclusioni del Baldo consiliatore: nel contesto del suo ampio ed articolato commento al Codice ${ }^{41}$, infatti, l'allievo di Bartolo, allorché si trova a discorrere dell'ormai familiare $\mathrm{Ad}$ commentariensem (C. 9.4.4) ed una volta esposta pianamente ed efficacemente l'esatta portata normativa della $l e x^{42}$, intesse alcuni riferimenti indiretti alla materia dell'evasione, riproponendo, peraltro, la dottrina della ficta confessio ${ }^{43}$ appena rinvenuta in Bartolo; allorquando, però, il discorso cade più diffusamente sulla natura della pena da riservare al custode inadempiente, dopo aver ribadito come "et custos et carceratus tenentur eadem poenam ${ }^{44}$, il giurista perugino commenta:

sed custos tenetur ratione culpae ad poenam capitalem praecise, non autem est sic in carcerato, ergo similitudo mala. Solvitur: dic, quod eadem poena est, sed non eadem culpa, nec circa idem, nec ex eadem lege, sed diversa. [...] Et nota quod est spetiale in custode carcerum, quod ratione culpae teneatur ad poenam capitalem ${ }^{45}$.

Nel definire più dettagliatamente la pena da riservare al custode inadempiente, dunque, Baldo, pur sottolineando come ben diverse risultassero essere le responsabilità del guardiano e del fuggitivo (essendo il primo punito a titolo di colpa ed il secondo a titolo di dolo), non mostra ritrosia alcuna nel parlare di pena capitale o nel rammentare come, pur con differenti premesse normative e titoli di responsabilità, la più grave delle punizioni fosse da riservare anche all'evaso.

Allorquando, cionondimeno, il medesimo Baldo si trovò a doversi paludare non più nelle disinteressate vesti di maestro ma in quelle, necessariamente più partigiane, di consiliator $^{46}$, è dato, fortunatamente, di recuperare un ulteriore tassello

\footnotetext{
${ }^{39}$ Da questo canto, si noti, il meccanismo predisposto da Bartolo non scongiura affatto l'irrogazione della più grave pena, sebbene riesca a circoscriverla al solo caso nel quale il reato per il quale il reo si trovava in carcere fosse già ex se meritevole della pena massima. ${ }^{40}$ Treggiari, 2019; Cortese, 2013.

${ }^{41}$ Baldus de Ubaldis, 1615.

${ }^{42}$ Ivi, fol. 212r: «custos carcerum fracto carcere per negligentiam sui custodis, non evitat poenam eum exhibendo, sed subiit supplicium quod ille qui fugit essere subiturus».

${ }^{43}$ Ibidem: «item nota quod licet contra effractorem carcerum inducatur quaedam ficta confessio $[\ldots] »$.

${ }^{44}$ Ibidem.

${ }^{45}$ Ibidem.

${ }^{46}$ Su Baldo consulente si rimanda a Cortese, 2013; Colli, 1991.
} 
da posizionare entro la complessità del suo pensiero: il "Consilium $X X X \mid l{ }^{47}$ del terzo volume dell'edizione poliana del 1575 , infatti, è dedicato anche alla questione "an fugiens de carcere habeatur pro confesso ${ }^{48}$. In proposito, esordisce Baldo, sta infatti il dictum della glossa ${ }^{49}$, secondo la quale bisogna rispondere affermativamente al quesito; ciononostante, il giurista perugino rimarca subito come "regulariter autem si quis fugit, fuga reddit eum suspectum, sed non convictus $»^{50}$. Persuaso che la portata normativa della glossa ordinaria «debet limitari ${ }^{51}$, Baldo propone una soluzione innovativa ${ }^{52}$, fondandola sulla capitale dicotomia processualistica ${ }^{53}$ tra inquisitio generalis ed inquisitio specialis:

nam aut quis detinetur pro generali inquisitione, et non habetur pro confesso, quia ficta confessio, sicut vera debet cadere super certo, et ideo debet crimen certum probari [...]. Aut detinetur pro inquisitione speciali criminis, et tunc aut fugit cum fractione, vel conspiratione et loquitur lex eos [D. 48.3.13, I. in eos] aut aliter, et tunc habetur non pro confesso, punitur tamen pro motu iudicis ${ }^{54}$.

Nella ricostruzione del Baldo consiliatore, dunque, è approntata un'espressa distinzione tra fuga occorsa nella prima fase del procedimento - allorquando il giudice si trova ancora nella fase dell'inquisitio generalis, ovvero intento solo ad "accertare l'effettiva commissione del reato» e ad "assumere le prime informazioni sullo stesso $»^{55}$ - ed evasione compiuta nel $"$ cuore ${ }^{56}$ del processo inquisitorio - ovvero quando il reo prende nome ed assume fattezze individuali ed il magistrato procedente «ricerca le prove idonee ad accertare la colpevolezza di una determinata persona $»^{57}$-: nel primo caso, sostiene Baldo (peraltro sanzio-

\footnotetext{
${ }^{47}$ Baldus de Ubaldis, 1575, foll. 9v-10r.

${ }^{48}$ Ivi, fol. $9 v$.

${ }^{49}$ Si veda gl. puniendi sunt, ad D. 48.3.13, I. in eos (Digestum Novum, 1558, fol. 984): «non aperit qua poena: sed videtur referre se ad poenam eius criminis, pro quo erat ibi, ut sic habeatur pro confesso».

${ }^{50}$ Baldus de Ubaldis, 1575, fol. $9 v$. A sostegno di tale asserzione Baldo richiama il testo della novella Auth., Exhibendis et introducendis reis, § si vero (che qui si citerà dall'edizione Volumen, 1558): "si vero etiam quidam iurent, quia observabunt, et ante, quam contestatio litis fiat, ab hac maxima dispareant civitate; licentiam esse etiam non facta litis contestatione adire actorem statutum iudicem, et hoc denunciare. Illum a vero (si quidem administrator sit), iubere omnimodo exhiberi reum tanquam periurum, et pene fui accusatorem per fugam factum» (ivi, foll. 1616-162).

${ }^{51}$ Baldus de Ubaldis, 1575 , fol. $9 v$.

${ }^{52}$ Perlomeno alla luce dei testi sinora esaminati.

${ }^{53} \mathrm{~A}$ proposito della quale, nella sterminata bibliografia, si vuole qui rimandare perlomeno a: Garlati, 2016; Condorelli, 2014; Dezza, 2013; Mausen, 2012; Dezza, 2002; Dezza, 1989.

${ }^{54}$ Baldus de Ubaldis, 1575, fol. $9 v$.

${ }^{55}$ Dezza, 2013, p. 59.

${ }^{56}$ Ibidem.

${ }^{57}$ Ibidem.
} 
nando nuovamente la teoria della ficta confessio ${ }^{58}$ già adombrata negli scritti del maestro), non può infatti parlarsi di ammissione di colpa ${ }^{59}$, giacché anche una finzione deve pur sempre riferirsi ad un che di sostanziale, di - verrebbe da dire ontologicamente sussistente (cosa che certo non può sostenersi a proposito del fatto criminoso nell'inquisitio generalis, qui suffragato unicamente da una ancora corroboranda notitia criminis); qualora, invece, la fuga sia occorsa allorquando l'immissione nell'inquisitio specialis era ormai già pienamente avvenuta, Baldo limita ulteriormente l'estensione della In eos (D. 48.3.13), confinandola al solo caso nella quale l'effrazione fosse avvenuta con violenza o a seguito di premeditata cospirazione. Se, però, l'evasione si era dispiegata senza uso di alcuna vis e senza alcuna pianificazione, la punizione del fatto andrà rimessa al motus iudicis, ossia agli ampi poteri arbitrari ${ }^{60}$ a questo rimessi.

Non è disagevole sottolineare come, nel contesto di questo responso, il Baldo consiliatore si periti di distinguere più dettagliatamente, rispetto al Baldo professore, alcuni dei casi ai quali la severa pena minacciata dalla compilazione giustinianea all'evaso non dovrà essere applicata: diverse, del resto, erano le circostanze che lo avevano portato ad esaminare la vexata quaestio, la quale ora appare certo più problematica di quella che si sarebbe potuto ipotizzare prima facie alla luce del solo, preliminare esame del trattato De carceribus.

La considerevole complessità del quadro sinora tracciato, a mente del quale son state rinvenute perlomeno tre soluzioni (pena capitale, ficta confessio e ricorso all'arbitrium iudicis) al quesito della repressione dell'evasione dal carcere, rende quanto mai necessario l'esame di alcune conclusioni fatte proprie, questa volta già in sede dottrinale, da quel «magnus practicus» ${ }^{61}$ che fu Alberico da Rosciate $^{62}$ (1290-1360), il quale produsse, sul tema in questione, una delle esposizioni scientifiche più complete e perspicue del XIV secolo, caratterizzata peraltro, come si vedrà subito, da una scrupolosa attenzione alla prassi quotidiana della giustizia: l'importanza della materia è subito segnalata dal giurista coll'incipit del suo commento, nel quale è proclamato esplicitamente come D. 48.3.13, I. in eos

\footnotetext{
${ }^{58}$ Un ulteriore esempio di ficta confessio nel contesto della materia processualpenalistica in Dezza, 2017.

${ }^{59}$ Giova peraltro notare come Baldo non formuli conclusioni sulle conseguenze della fuga per l'evaso durante l'inquisitio generalis, limitandosi a rappresentare come al suo caso non possa applicarsi la teoria della ficta confessio: la ragione di ciò è probabilmente da ricercare nella natura del consilium preso in esame, ove appare evidente, dal prosieguo dello stesso, come la fuga fosse avvenuta in altro momento del procedimento (senza peraltro evidenziare con precisione quando).

${ }^{60}$ Per il rapporto tra pena ed arbitrium nel diritto comune si rimanda perlomeno agli studi di Meccarelli, 2016 e Meccarelli, 1998, oltre che alle suggestive prospettive continuamente dischiuse in Schnapper, 1973 ed in Schnapper 1974.

${ }^{61}$ La locuzione si trae da Cortese, 1995, p. 423.

62 Storti, 2013.
} 
sia «lex notabilis» ${ }^{63}$.

I punti nevralgici della norma risultano essere tre: anzitutto, Alberico fa rilevare come codesta lex sanzioni penalmente la condotta di chi, recluso in carcere, cospiri con gli altri detenuti al fine di evadere dalla prigionia; per ciò che riguarda la sanzione edittale, invece, il giurista espone chiaramente che, in caso di cattura, i cospiratori possono essere puniti immediatamente, come se avessero confessato il crimine per il quale erano stati originariamente imprigionati (e ciò anche se, in seguito, si accertasse la loro innocenza in relazione al primo delitto); infine, il da Rosciate conferma la natura premiale dell'ultima parte della norma, concludendo come i detenuti che informino le autorità carcerarie della fuga dei compagni vadano esentati da qualsiasi ulteriore pena ${ }^{64}$. Cionondimeno, aggiunge subito Alberico, la lex in commento risulta essere talmente frequentata dalla prassi ( ... quia ista lex mihi saepe occurrit in practica ...») e così rilevante quale argomento di discussione tra i giuristi ("... et ea satis ruminavi cum magis prudentibus ...») da meritare una trattazione più approfondita ( "... eam clarius aperio» ${ }^{65}$ ).

Prima facie, infatti, sembrerebbe doversi concludere che colui che fugge dal carcere con effrazione debba essere condannato ad una pena capitale: in tale direzione, peraltro, condurrebbero le parole tanto della De iis (D. 47.18.1) quanto della Milites agrum (D. 49.16.13). Alcuni giuristi, infatti, hanno sostenuto che, nonostante la chiara determinazione della In eos (D. 48.3.13), il fuggitivo andrebbe comunque punito con pena di natura capitale, citando a sostegno delle proprie asserzioni l'aggettivo comparativo "amplius» che fa capolino in quest'ultima ${ }^{66}$. La posizione, del resto, secondo la quale, in realtà, tale ultima lex non specificherebbe esplicitamente la natura capitale della pena (interpretazione a proposito della quale si era già, peraltro, concentrata la disapprovazione di Oldrado da Ponte ${ }^{67}$ ),

\footnotetext{
${ }^{63}$ Albericus de Rosate, 1585, fol. $175 \mathrm{v}$.

${ }^{64}$ Albericus de Rosate, 1585, fol. 175v: «et dicit, quod si aliqui carcerati conspiraverunt ad invicem, ut fractis carceribus evadant, si postea recipiantur puniri statim possunt, tanquam confessi de crimine, propter quod primo erant carcerati, etiam si forent innocentes de dicto crimine. Secundo quod si quis eorum conspirationem revelat, relevatur a poena».

65 Ibidem.

${ }^{66}$ Albericus de Rosate, 1585, fol. 175v: «et primo videtur, quod fugiens de carcere eo fracto puniatur poena capitali, ut supra de effract.I.1.iis [D. 47.18.1, I. de iis], de poen.I.si quis aliquem.§.miles [D. 48.19.38, I. si quis aliquid, § miles] et de re mili.I.milites.§.eius qui [D. 49.16.13, I. milites agrum, § eius fugam]. Dicunt quidam, quod hic intelligitur secundum determinationem illarum si ut habeant pro confesso de crimine, pro quo erat incarceratus, licet esse innocens, ut dicit glossa et nihilominus capite puniant, ut dictis legibus et hoc innuit verbum, amplius».

${ }^{67}$ Albericus de Rosate, 1585, fol. 175v: «et hanc dicunt fuisse opinio domini Oldradi». Sul giurista lodigiano si può ora rimandare a Valsecchi, 2013a e ad Ead., 2013b oltre che ad Ead., 2000.
} 
è da Alberico qualificata come "tenui opinionem» ${ }^{68}$, in ciò coadiuvato dal dictum concorrente di diversi «iudices Potestatis qui erant valentes viri» ${ }^{69}$ coi quali egli ebbe occasione di discorrere della cosa.

Altri ancora, prosegue Alberico, preferiscono conferire un maggior peso alle circostanze nel contesto delle quali ed in virtù delle quali l'evasione è potuta riuscire: in tale prospettiva, la pena capitale sarebbe riservata unicamente a coloro che abbiano perpetrato la propria fuga usando violenza contro i custodi; a coloro che, invece, siano evasi senza l'applicazione di alcuna vis, toccherebbe unicamente di essere considerati ficti confessi del crimine per il quale erano stati originariamente incarcerati ${ }^{70}$.

Non manca, conclude quindi il da Rosciate, lo schieramento di coloro che hanno preferito far risaltare soprattutto le responsabilità sostanziali del carcerato: secondo costoro, quindi, l'evasione con effrazione comporta la condanna al patibolo solo nel caso il fuggitivo sia effettivamente dichiarato colpevole del reato per il quale era stato ristretto; nell'evenienza, invece, di un giudizio conclusosi con sentenza assolutoria, le conseguenze per l'evaso si limiteranno a quelle già esposte per la sola ficta confessio e, quindi, alla pena prevista per il reato originario - cosa che, interviene subito Alberico, può accadere solo e solamente nel caso il reato originario sia stato effettivamente realizzato da qualcun altro, apparendo altrimenti manifestamente iniquo che uno debba essere punito per un fatto che non solo non ha commesso ma non è nemmeno mai esistito ${ }^{71}$ in natura (verrebbe qui da dire ricorrendo a categorie proposte dal già citato Yan Thomas ${ }^{72}$ ) -. Per ciò che riguarda l'evento effrattivo in sé, invece, quest'ultima soluzione dottrinaria rimette all'arbitrium iudicis la concreta individuazione della pena da irrogare ${ }^{73}$, in ciò confortata dal dettato della seconda ${ }^{74}$ lex del titolo De effractoribus ${ }^{75}$.

\footnotetext{
${ }^{68}$ Albericus de Rosate, 1585 , fol. $175 v$.

${ }^{69}$ Ibidem.

${ }^{70}$ Ibidem: «alii dicunt, aut carcer fuit effractus illata violentia custodibus, et tunc puniant capite, ut dictis legibus. Aut nulla violentia custodibus illata, et tunc habeant pro confessis de criminibus pro quibus erant incarcerati, et ultra non puniantur».

${ }^{71}$ Ibidem: «alii dicunt, aut ille, qui effracto carcere evasit erat nocens de delicto, pro quo detinebat, et tunc puniatur sicut causa deposcit scilicet capite, ut dictae leges. Aut est innocens, et tunc habet pro confesso de illo crimine, et ultra non puniatur, quod puto verum si illud crimen commissum erat ab aliquo [...]; alias nullo modo ex tali confessione ficta punietur, quia et ex vera confessione confessione non puniretur».

${ }^{72}$ Sul rigetto della dottrina medievale della tecnica della fictio legis e sull'argine a questa eretto col concetto di natura si veda il già citato Yan Thomas, 2016, e specialmente pp. 59-90.

${ }^{73}$ Albericus de Rosate, 1585, fol. 175v: «propter effracturam tantum puniret arbitrio iudicantis, cum hoc casu poena non reperiatur determinata, ut arguitur supra I.2.§expilatores [rectius: D. 47.18.1, I. de iis, § expilatores]».

${ }^{74} \mathrm{Ma}$, in realtà, si tratta di D. 47.18.1, I. de iis, § expilatores.

${ }^{75}$ Digestum Novum, 1558, fol. 959: «expilatores, qui sunt atrociores fures: hoc enim est
} 
Riferite diffusamente e con dovizia di particolari le diverse posizioni delle scuole di pensiero della dottrina antica e coeva, Alberico passa ad illustrare le proprie conclusioni:

mihi autem studiose hanc legem ruminanti, videbatur, et videtur dicendum, quod haec lex loquatur quando carcerati conspiraverunt de carcere frangendo, non tamen perfecerunt conspirationem, vel fracturam, vel quod detecta fuit conspiratio, ut in fine legis, vel quia alias non potuerunt, vel noluerunt [...]; et quamvis isto casu sint innocentes, et litera dicat, quod puniendi sunt, et non determinet poenam, crederem ea arbitrariam arbitrio iudicis ut praedixi [...]. Si autem non tantum conspiraverunt, sed conspirationem ad effectum perduxerunt, et effracto carcere fugerunt, tunc puniantur capite, ut in lex contraria habita tamen forte distinctio et non male, utrum culpa custodum, an sine culpa evaserint, ut dicta I.1. [D. 47.18.1, I. de iis] et utrum violenta fuerit illata custodibus vel non ${ }^{76}$.

La distinzione proposta dal giurista bergamasco è qui fondata sulla fondamentale dicotomia tentativo/consumazione ${ }^{77}$ : allorché, infatti, l'evento effrattivo non sia perfezionato (essendo indifferente che alla cospirazione non si sia dato seguito perché, come esplicitamente contemplato nella In eos, alcuni dei compagni di prigionia hanno rivelato l'intento dei cospiratori ovvero perché questi non hanno potuto o voluto portare a compimento il disegno criminoso), Alberico suggerisce di rimettere la soluzione della portata punitiva ai poteri arbitrari del giudice, non essendo contemplata alcuna pena edittale propria per tale evenienza; diverso, invece, il caso nel quale la cospirazione abbia effettivamente realizzato la fuga dei detenuti, evenienza in ragione della quale è richiamata tutta la durezza delle previsioni sanzionatorie della littera legis delle De iis (D. 47.18.1) e Milites agrum (D. 49.16.13).

Alla severità del dettato normativo, cionondimeno, Alberico contrappone due eccezioni mitigatorie, la prima anch'essa di esplicita discendenza letterale e la seconda ripresa da una delle correnti dottrinarie precedentemente citate: nell'un caso, infatti, contribuirebbe a dispiegare più miti sanzioni il concorso della culpa in vigilando delle guardie carcerarie (expressis verbis introdotto nell'economia del giudizio dalla De iis); nell'altro caso, invece, si farebbe risaltare la presenza o l'assenza di una qualsiasi vis usata dai fuggitivi contro i custodi delle carceri, riservando così una pena più lieve per coloro che abbiano portato a compimento l'evasione senza colpo ferire ${ }^{78}$.

expilatores, in opus publicum, vel perpetuum, vel temporarium dari solent; honestiores autem ordine ad tempus moveri vel patriae fines iuberi excedere; quibus nulla specialis poena rescriptis principalibus imposita est. Idcirco causa cognita liberum erit arbitrium statuendi ei, qui cognoscit» (D. 47.18.1, I. de iis, § expilatores).

${ }^{76}$ Albericus de Rosate, 1585 , fol. $175 \mathrm{v}$.

${ }_{77}$ A proposito della quale il riferimento è Isotton, 2006.

${ }^{78}$ Si rammenterà come, tra le correnti dottrinarie citate nel discorso albericiano, la proposta di coloro che ritenevano di dover agire in tal senso era quella di considerare quali 


\subsection{Tra inquisizione ed actus licitus: il contributo del diritto canonico}

I dibattiti interpretativi che agitarono la dottrina civilistica nel corso del Trecento - e la corrispondente varietà di opinioni - non sembrano trovare corrispondenza nel versante canonistico dell'utrumque ius: il fondamento "legislativo" del diritto canonico contemporaneo (ovverosia le decretali dei romani pontefici), unitamente ai vasti privilegi concessi ai giudici in materia di repressione dell'errore ereticale, infatti, produssero un quadro piuttosto perspicuo in tema d'evasione, anch'esso caratterizzato, come peraltro quello civilistico testé celermente illustrato, da una certa qual severità (durezza, questa, che solo nei secoli successivi, come si vedrà, il diritto canonico riuscirà, perlomeno parzialmente, a superare, forse ispirato anche da alcune riflessioni d'ambito più propriamente morale che giuridico ${ }^{79}$ ma propalate da un gigante del pensiero come Tommaso d'Aquino). Come già anticipato, la prospettiva che si intende adottare per dissodare preliminarmente il tema sarà quella delle statuizioni pontificie e della successiva riflessione dottrinale in tema d'eresia, le quali, ad unanime giudizio della storiografia $^{80}$, tanto hanno contribuito a fecondare il diritto penale secolare e tanto, a loro volta, son state stimolate nel loro sviluppo da codesto contatto osmotico ${ }^{81}$ con la realtà extra ecclesiale.

Il punto di partenza per un esame non eccessivamente superficiale della questione può essere rappresentato, e non per la prima volta che ciò che concerne gli studi sul carcere ${ }^{82}$, da una decretale di Bonifacio VIII (1295-1303): I'occasione per l'emanazione del rescritto era stata fornita al pontefice dalla necessità di meglio circoscrivere la giurisdizione dell'Inquisizione a seguito della nomina di un giudice della fede per la regione di Bordeaux ${ }^{83}$, venuto ai ferri corti coll'ordinario locale. Oltre a concedere agli inquisitori ampi poteri istruttori, la decretale

ficti confessi i detenuti che fossero fuggiti senza usare violenza a nessuno (evitando loro, perlomeno, l'ultimo supplizio).

${ }^{79}$ Sulla contiguità tra questi due saperi si rimanda ai primi riferimenti bibliografici in Donati, 2020b.

${ }^{80}$ Si rimanda sul punto ai già citati studi di Pifferi, 2019; Dezza, 2013; Geltner, 2012 oltre che a Padoa Schioppa, 2020; Pennington, 2019; Gigliotti, 2018; Chiodi, 2015; Pihlajamäki, Korpiola, 2014; Grossi, 2013, pp. 7-192.

${ }^{81}$ L'aggettivo si riprende da Padoa Schioppa, 2003, p. 121, ove si abbraccia la grandezza intellettuale di un «fenomeno di osmosi, in virtù del quale - pur mantenendo il diritto canonico il suo carattere di ordinamento ben distinto dagli altri ordinamenti giuridici, anche per il rapporto inscindibile che lo lega ai valori religiosi - esso accoglie non pochi elementi di altri diritti, di altri metodi argomentativi e di altri prodotti della cultura. E a sua volta cede ad altri rami del diritto elementi suoi propri».

${ }^{82}$ Donati, 2020a, pp. 139-141.

${ }^{83}$ Si veda Casus, ad VI. 5.2.12, c. ut commissi: "Papa deputavit inquisitorem haereticae pravitatis in provincia Burdegalensis. Quaeritur de potestate ipsius inquisitoris» (la citazione di trae da Liber Sextus, 1582, col. 631). 
Ut commissi (VI. 5.2.12) distingue tra atti che l'inquirente può adottare autonomamente (quale, ad esempio, quel penetrante potere di sequestro concernente qualsiasi scritto possa avere anche un pur minimo valore per la repressione dell'eterodossia ${ }^{84}$ ) e atti che invece vanno de necessitate disposti col concorso dell'ordinario diocesano (tra i quali è annoverata, per l'appunto, la facoltà di inasprire o mitigare la durata e le condizioni della prigionia per i penitenti ${ }^{85}$ che siano già stati condannati $\left.{ }^{86}\right)$.

Pur non contemplata espressamente da Bonifacio nella Ut commissi, l'evasione giunse rapida ad affaccendare le menti dei canonisti: i Commentaria ${ }^{87}$ dell'Arcidiacono ${ }^{88}$ (†1313), da questo punto di vista, hanno avuto non solo il merito di essere stati tra i primi a corredare le statuizioni pontificie appena descritte ma anche di riuscire talmente convincenti da guadagnarsi il concorso ${ }^{89}$ più o meno incondizionato di Giovanni d'Andrea ${ }^{90}$, di Pietro d'Ancarano ${ }^{91}$ e di Domenico da San Gimignano ${ }^{92}$. Dopo aver trattato degli ampi poteri dell'inquisitore in materia carceraria ${ }^{93}$, infatti, Guido insegna come

\footnotetext{
${ }^{84}$ Ivi, coll. 632-633: «necnon faciendi a quibuslibet assignari vobis libros, seu quaternos, et alia scripta, in quibus Inquisitiones factae, ac processus per quoscumque auctoritate Sedis Apostolicae, vel legatorum eius, habiti contra haereticos continentur [...] concedimus facultatem».

${ }^{85}$ Sul potere concesso agli inquisitori di ricevere abiure e pentimenti, nonché sul vasto arsenale di pene medicinali a loro disponibile si rimanda agli studi di Errera, 2018 e Santangelo Cordani, 2017.

${ }^{86}$ Ibidem: «et illorum, qui vestris mandatis obedientes humiliter stant propter haeresim in carcere vel muro reclusi, poenam, una cum praelatis, quorum iurisdictioni subsunt, mitigandi vel mutandi, cum videritis expedire [...] concedimus facultatem».

${ }^{87}$ Archidiaconus, 1577.

${ }^{88}$ Su Guido da Baisio si veda Liotta, 2013.
}

${ }^{89}$ Si noterà, nei passi che seguono, una vicinanza quasi verbatim ac litteratim alle riflessioni dell'Arcidiacono che si riporteranno subito: Iohannes Andreae, 1581, fol. 139r («qui postea detrusi sunt in carcerem [...] sed si tales sponte carcerem exiverant, quilibet excusationem legitimam non habens potest ut haereticus condemnari, quia fingitur ficte conversus, simulatae confessus, vel erroris pristini recidivus»); Petrus de Ancharano, 1583, fol. 391 («detrusi ergo in carcere [...] de quo si exiverint, possunt ut haeretici condemnari, secundum Archidiaconum»); Dominicus a Sancto Geminiano, 1578, fol. 275r («tamen dicit Archiadonus [...] quod si tales sponte carceres exiverint, qui non habent excusationem legitimam, possunt ut haeretici condemnari, quia finguntur ficte conversi, et simulatae confessi, vel erroris pristini recidivi»).

${ }^{90}$ Un primo riferimento in Bartocci, 2013.

${ }^{91}$ Sul quale si può vedere Condorelli, 2015, nonché Cortese, Pennington, 2013.

${ }^{92}$ Cfr. Quaglioni, 1991.

${ }^{93} \mathrm{E}$ aver sottolineato come, in effetti, nel caso di coloro che detestino le proprie opinioni eterodosse, la reclusione non sia tanto una pena quanto un periodo di penitenza, necessario alla resipiscenza e all'inquisitore per rendersi conto della solidità della sua conversione: «ista carceris reclusio non est tam ad poenam crminis, quam ad cautelam 
detrusi in carcerem [...] si tales sponte carcerem exiverunt, si legitimam excusationem non habent, possunt tamquam haeretici condemnari: nam presumitur ficta conversio, et confessio simulata, et materia veteris erroris recondita ${ }^{94}$.

Gli aspetti di questo passo che possono, forse, più colpire l'attenzione dell'interprete, al di là della perspicuità che connota l'argomentare dell'Arcidiacono, sono anzitutto la rilevanza riconosciuta dal giurista all'elemento soggettivo delle azioni del penitente - il quale interessa tanto nel momento dell'evasione quanto in quello della detestazione del peccato contro la fede - e la presenza di una scriminante, dai confini piuttosto ampi, data dalla legittimità del proprio agire: di ulteriore rilievo, altresì, la mancanza di particolari approfondimenti (anche nella dottrina successiva citata) relativi alla condanna dei penitenti quali eretici, comprensibile, però, alla luce del fatto che l'originaria statuizione bonifaciana aveva a che fare con quei rei confessi che erano già stati perdonati, sub condicione resipiscentiae, per i loro delitti contro la fede, rappresentando la prigionia null'altro che un momento successivo di conferma e valutazione dell'effettiva conversione.

Le conclusioni dei canonisti, del resto, trovarono piena conferma in quello che è stato definito autorevolmente come il più «importante manuale medievale di procedura inquisitoriale ${ }^{95}$ : allorché, infatti, Nicolás Eymerich ${ }^{96}$ (†1399) si trovò, alla quaestio 97 del suo Directorium inquisitorum ${ }^{97}$, a riflettere proprio del caso già preso in considerazione anni prima da Bonifacio VIII, I'inquisitore domenicano così formulò le proprie conclusioni:

nonagesima septima quaestio est: utrum episcopus et inquisitor possint procedere contra talem ad carcerem condemnatum, et alias paenitentiatum, tamquam contra impaenitentem, vel relapsum, si iniunctas sibi paenitentias violavit, seu aufugit de carcere, ad quem fuerat condemnatus? Respondemus quod sic [...]; possunt igitur procedere contra tales, huiusmodi iniunctas sibi poenitentias violantes, et carceres fugientes: ita quod si legitimam excusationem non probaverint, sunt ut impaenitentes haeretici condemnandi. Nam praesumitur ficta conversio et simulata, et materia veteris erroris recondita ${ }^{98}$.

L'esplicito riferimento, da parte dell'Eymerich, alle conclusioni dell'Arcidiacono $^{99}$ è del resto implicitamente suffragato, pur su un terreno più generale di quello strettamente concernente la procedura inquisitoriale, da un altro grande canonista, quel Niccolò dei Tedeschi (†1445) conosciuto anche come Abbas

\footnotetext{
[...]; nec noceant, ne alios inficiant, ut appareat, an in tenebris ambulent, an in luce, an ibi peniteant» (Archidiaconus, 1577, fol. 115v).

${ }^{94}$ Archidiaconus, 1577, fol. $115 v$.

${ }^{95}$ Errera, 2000, p. 20.

${ }^{96}$ A proposito del quale si rimanda a Borromeo, 2010.

${ }^{97}$ Eymerich, Peña, 1587.

98 Ivi, fol. 643.

99 Ibidem: "et his concordat Archidiaconus in c.ut commissi».
} 
Panormitanus a cagione della duplice dignità arcivescovile ed abbaziale ${ }^{100}$ :

quid autem si carceratus frangit carcerem? De iure civili est est puniendus poena capitali, etiam si innocens sit et mitius punitur si sine fractione per incuriam custodis cepit fugam, de quo dicendum ut in I.1.et 2.ff.deeffra. [D. 47.18.1-2], sed de iure canonico potest ad depositionem procedi, et data incorregibilitate ad traditionem curiae secularis ${ }^{101}$.

L'insegnamento del Panormitano $^{102}$ testé riproposto (così come il passo del De carceribus riportato in apertura del paragrafo precedente) mostra anzitutto come, a cavallo dei secoli XIV e XV, ordinamento civile e canonico comunicassero oramai senza particolari ostacoli: alla domanda, infatti, su quale fosse la pena da riservare a chi fosse evaso per vim dalla prigionia, il canonista non esita ad istituire un confronto tra il destino riservato al fuggitivo secondo il diritto civile e secondo il diritto canonico. Oltre a riproporre il contenuto normativo delle due leges del titolo De effractoribus, il Panormitano - ed è questo il punto sul quale si vuole maggiormente attrarre l'attenzione del lettore - congiunge, in termini avversativi, le disposizioni del diritto romano (descritte con tinte funeste ${ }^{103}$ ma pur sempre addolcite dalla presenza di una minore severità data dalla presenza della possibile incuria delle guardie carcerarie) con quelle del diritto della Chiesa, ove I'unica cautela che pare separare il reo dall'ultimo supplizio ${ }^{104}$ è la natura potenziale del verbo che regge l'ultima proposizione: in ciò sembra possibile riscontrare - tale parendo essere il significato da attribuire a quel «sed» avversativo - una certa, conclamata contrapposizione (perlomeno nel pensiero del Panormitano) tra le disposizioni dello ius civile e dello ius canonicum, fondata su una maggiore durezza di quello rispetto a quest'ultimo (già peraltro caratterizzato in sé, come detto, non da nitente mitezza).

L'impressione generale che può emergere da questo rapido excursus, condotto attraverso alcune fonti canonistiche deI XIV secolo, viene ad essere ulteriormente circostanziata ed arricchita se si allarga il punto di vista ad alcune riflessioni ${ }^{105}$,

\footnotetext{
${ }^{100}$ Sul Panormitano ed i suoi commentaria il rimando è a Condorelli, 2019 e ad Id., 2013. ${ }^{101}$ Panormitanus, 1588, fol. $192 v$.

102 II quale, lo si sottolinea, non si riferisce a VI. 5.2.12, c. ut commissi (la quale non risulta commentata, perlomeno nell'edizione che si è consultata) ma bensì a X. 5.9.5, c. $a$ nobis, una disposizione concernente la miglior penitenza da infliggere a chierici che, rei di apostasia e già detenuti sub custodia, si rifiutino pervicacemente di sottomettersi a migliori consigli (l'evidente somiglianza con il caso dell'eretico abiurante e detenuto pro resipiscentia è ciò che probabilmente ha spinto l'anonimo del De carceribus a citare questo titolo delle decretali gregorianee).

${ }^{103}$ E riproponendo le conseguenze di quella fictio legis che fa del fuggitivo un colpevole nonostante la sua innocenza (etiam si innocens sit).

104 Il linguaggio intessuto di riferimenti al processo antiereticale (traditio brachio seculari) può essere meglio compreso riferendosi a Santangelo, 2017, pp. 193-203.

${ }^{105}$ Le quali qui si citeranno traendole da Thomas Aquinas, 1594.
} 
distinte ma contigue ${ }^{106}$, di Tommaso d'Aquino in tema di giustizia: alla questione dell'evasione ${ }^{107}$, infatti, è in parte ${ }^{108}$ dedicato l'articulus quarto della quaestio ${ }^{109}$ LXIX della sua Summa (II-II, q. 69, a. IV), nel corso del quale il doctor Ecclesiae sviscera il quesito "utrum liceat condemnato ad mortem se defendere, si possit»" Pur circoscritto al caso particolare del condannato a morte, il pensiero del "bue muto", muovendosi lungo il familiare percorso sistematico propositio/oppositio/ solutio della quaestio di tradizione scolastica ${ }^{111}$, affronta infatti senza mezzi termini la problematica della liceità dell'evasione:

videtur quod licet condemnato ad mortem se defendere, si possit. [...] Sicut aliquis sententiam mortis contra se latam subterfugit resistendo, ita etiam fugiendo, sed licitum esse videtur, quod aliquis se a morte per fugam liberet, secundum illud Eccl.9. [Sir 9, 13]: longe esto ab homine potestatem habente occidendi; et non vivifacandi. Ergo etiam licitum est reo resistere [...].

Sed contra est, quod dicit Apostolus Ro.13 [Rm 13, 2]: qui potestati resistit, Dei ordinationi resistit; et ipsi sibi damnationem acquirit [...].

Respondeo dicendum quod aliquis damnatur ad mortem dupliciter. Uno modo iuste, et sic non licet condemnato se defendere. [...] Alio modo condemnatur aliquis iniuste, et tale iudicium simile est violentiae latronum, secundum illud Ezech.22 [Ez 22, 27]: principes eius in medio illius quasi lupi rapientes praedam ad effundiendum sanguinem. Et ideo sicut licet resistere latronibus, ita licet resistere in tali casu malis princibus [...].

${ }^{106}$ Si vedano in proposito Nobile Mattei, 2019, pp. 186, 189-190, 194, 199, 208 e Cavina, 2013a, pp. 102, 120, 122 per alcuni esempi intorno alla rivelanza del pensiero di Tommaso per la storia del diritto penale.

107 II tema più generale della liceità dell'incarcerazione è invece affrontato alla II-II, q. 65, a. III (Thomas Aquinas, 1594, foll. 157r-v).

${ }^{108}$ Sussistono, cionondimeno, pochi dubbi circa il fatto che, anche ad occhi contemporanei, il vero nocciolo della quaestio fosse rappresentato dalla questione dell'evasione: l'apparato di glosse che, nell'edizione consultata (Thomas Aquinas, 1594), accompagna il testo dell'Aquinate dichiara apertamente come "quaestiunculae multae occurrunt circa doctrinam traditam in responsionem ad secundum 4. ar. [II-II, q. 69, a. IV] de fuga iuste damnati ad mortem», tra le quali si segnalano, ad esempio: "an iuste damnatus licite possit dirumpere vincula, et compedes quibus alligatus est, ut possit fugere»; «an possit effringere carcerem licite»; "an liceat aliis adiuvare hominem huiusmodi ad fugiendum, dando ei consilium, et auxilium» (tutte le citazioni si son tratte da Thomas Aquinas, 1594, fol. 167r). Sul cardinal Caietano, autore delle glosse testè riportate, può vedersi Pignata, 2013.

${ }^{109}$ Consacrata al tema «de peccatis quae sunt contra iustitia» (Thomas Aquinas, 1594, foll. 165v-168r).

${ }^{110}$ Ivi, fol. 168 r.

${ }^{111}$ Sul fondamentale strumento concettuale e sul suo fortunato innesto nell'arsenale metodologico della scienza giuridica il rimando è a Padoa Schioppa, 2003, pp. 138-141 e a Bellomo, 2000; Id., 1974. 
Ad secundum dicendum, quod nullus ita condemnatur, quod ipse sibi inferat mortem, sed quod ipse mortem patiatur, et ideo non teneatur facere id, unde mors sequatur, quod est manere in loco, unde ducatur ad mortem. Tenetur tamen non resistere agenti, quin patiatur quod iustum est eum pati. Sicut etiamsi aliquis sit condemnatus, ut fame moriatur non peccat si cibum sibi occulte ministratum sumat, quia non sumere, esset seipsum occidere ${ }^{112}$.

L'incipit della quaestio è dedicato alla citazione di un passo del Siracide, nel quale è rievocato l'insegnamento sapienziale secondo il quale saggio è colui che se ne sta appartato "dall'uomo che ha il potere di uccidere» $(\operatorname{Sir} 9,13)$ : a questa inferenza, che tenta di fondare la liceità del condannato a morte di fuggire, l'oppositio contrappone una ben più gravida di conseguenze massima di Paolo, secondo il quale "chi si oppone all'autorità, si oppone all'ordine stabilito da Dio» $(R m$ 13,2). La soluzione all'apparente disarmonia tra i passi biblici è da Tommaso proposta a partire da una distinctio, anch'essa dalla storia fortunata ${ }^{113}$ : vi è infatti, da una parte, il caso di chi sia stato condannato a morte iuste ma anche il caso di chi, dall'altra, si veda condotto al patibolo iniuste. Nella prima eventualità, la resistenza del reo attira su di sé tutta la forza repressiva del dictum paolino, facendo del disubbidiente non solo un criminale ma anche un attentatore dell'ordine naturale delle cose; nel secondo caso, invece, l'atto di lesione proviene dall'autorità dispiegata ingiustamente, perciò simile ai quei capi di Israele che avevano abbandonato le vie del Signore, trasformandosi da pastori amorevoli in lupi voraci, meritevoli dello sdegno di Dio. Contro questi falsi governanti, prosegue Tommaso, la resistenza si trasforma da atto perturbatore dell'ordine delle cose in legittima difesa. Anche nel caso, però, di colui che sia stato condannato legittimamente al patibolo, il doctor angelicus pare dischiudere una prospettiva di salvezza: nessuno, infatti, pur condannato a morte, è obbligato ad eseguire da sé la sentenza esiziale; così come il condannato a morte per inedia non pecca in alcun modo se si nutre del mangiare consegnatogli surrettiziamente dalle guardie, ben potrà il recluso approfittare di un'occasione propizia per non essere condotto al patibolo (ed è qui che è dato registrare un implicito assenso all'eventualità di una fuga). Esiste, cionondimeno, un limite espresso a tale possibilità: Tommaso, infatti, rimarca come non sia lecito, per il reo, "resistere agenti»" ${ }^{114}$, in ciò escludendo, con ogni probabilità, che la fuga possa essere realizzata usando violenza contro le guardie.

Allargato il campo visivo anche alle ariose ma concretissime riflessioni di uno dei più grandi intellettuali del Medioevo, sembra di potersi affermare, con un certo grado di sicurezza, che tanto il diritto civile quanto il diritto canonico, sul finire del quattordicesimo secolo, avessero inquadrato il problema dell'evasio-

\footnotetext{
112 Thomas Aquinas, 1594, fol. 168r.

${ }^{113}$ La si rinverrà anche infra a breve.

${ }^{114}$ Thomas Aquinas, 1594, fol. 168r.
} 
ne ancorando, mutatis mutandis, ciascuna delle tre soluzioni proposte ${ }^{115}$ (pena capitale, ficta confessio e ricorso all'arbitrium iudicis) ad un fondamento legislativo (romanistico o pontificio che fosse), finendo comunque per proporre anche soluzioni di discendenza non direttamente testuale (le varie correnti dottrinarie enumerate dal da Rosciate si rivelano, in proposito, particolarmente eloquenti): non può cionondimeno mancarsi di far rilevare una particolare attenzione degli interpreti (le parole di Alberico risultano, a tal proposito, particolarmente illuminanti) nel distinguere caso da caso, nel tentativo di circoscrivere sempre più l'efficacia delle severe conseguenze discendenti da una meccanica irrogazione delle pene fulminate dal diritto romano - in ciò, forse, resi più malleabili e solleciti dalla comprensione delle non certo invidiabili condizioni dei carcerati, le quali erano perfettamente note ai giuristi che spesso sedevano negli organi comunali preposti al governo delle istituzioni penitenziarie ${ }^{116}$ - Sullo sfondo, del resto, si stagliarono, con tutto il loro prestigio, le riflessioni di Tommaso in merito alla iustitia della carcerazione e, più in particolare, sulla liceità per il prigioniero di non concorrere in alcun modo alla propria esecuzione, dandosi ad una fuga che non apportasse nessun male a chi doveva vigilare sulla sua detenzione.

I secoli successivi, cui occorre ora volgere lo sguardo, innalzeranno su queste basi una fitta rete di edifici dottrinali, dimostrando come il problema dell'evasione riuscisse a stimolare costantemente la riflessione dei giuristi quale problema sempre attuale ed indimenticato.

\subsection{La viva voce della prassi penalistica: la prima età moderna e la vittoria dell'arbitrium iudicis}

La nascente scienza criminalistica non perse l'occasione, a partire dal secolo quindicesimo, per collocare in termini maggiormente sistematici la problematica dell'evasione: un buon punto di partenza, in proposito, è offerto dal tractatus ${ }^{117}$ di Angelo Gambiglioni d'Arezzo ${ }^{118}(+1461)$, il quale, trovandosi a discorrere della natura del carcere quale strumento tanto procedurale quanto afflittivo, affrontò nei seguenti termini la questione:

quid si quis positus fuit in carcere pro aliquo crimine, etiam si dictum crimen non

\footnotetext{
${ }^{115}$ L'esito tripartito delle riflessioni della dottrina trecentesca venne, in effetti, anticipato già sul finire del Duecento, con una precocità rimarchevole, da Bonifacio Antelmi, secondo il quale "si carcerati ruptis vinculis et effracto carcere evadunt, poena capitali puniuntur, ut ff.de effract.I.1.in prin. [D. 47.18.1, I. de iis] vel alia extraordinaria poena, ut d.I.1 vel puniuntur poena illius delicti pro quo sunt carcerati, etiam si sunt innocentes, ut habeantur pro confessis propter fugam, ut ff. eo.I.in eos [D. 48.3.13, I. in eos]» (Pseudo Vitalinus, 1578, fol. 461r). Sull'Antelmi può rimandarsi a Maffei, 2020.

${ }^{116}$ Come rilevato diffusamente in Geltner, 2012.

${ }^{117}$ Angelus Aretinus, 1599.

${ }^{118}$ Per la cui vita e produzione si rimanda a Maffei, 2013b.
} 
commiserit, tamen si effracto carcere aufugerit, habetur pro confesso dictum crimen: et contra eum, ut tamquam dictum crimen commisisset, et tanquam contra confessum dictum crimen procedi potest: ut est textus et ibi glossa et Bartolus in I.in eos.ff.de cust.reo. [D. 48.3.13, I. in eos] $]^{119}$.

Giova qui sottolineare senz'altro come l'Aretino - in termini del tutto perspicui non lasci trasparire molti dubbi sull'individuazione delle conseguenze più opportune per l'evaso, richiamando in toto la dottrina della ficta confessio, sorretta dall'autorità di Bartolo, e non menzionando nemmeno la pena capitale: un autore sul quale, invece, la distinctio qui già illustrata riferendosi alla dottrina dell'Aquinate tra iusta ed iniusta carcerazione deve aver prodotto una certa, seppur non esplicita, impressione è il bolognese Ippolito Marsili ${ }^{120}$ (1450-1529). Nella sua practica ${ }^{121}$, il giurista accorda ampio spazio alla materia carceraria ${ }^{122} \mathrm{e}$, per ciò che riguarda più da vicino il tema dell'evasione, utilizza espressamente il concetto di iusta carceratio, elevandolo a criterio distintivo per l'irrogazione della pena capitale:

quaeri etiam potest ultra praemissa qua poena puniatur fugiens de carcere? In quo dicas quod punitur poena mortis. [...]

Sed praedicata intelligas in frangente carcere et postea fugiente, nam talis punitur poena capitis. Sed secus puto esse in carcerato qui reperit ostium apertum et tunc aufugit, quia talis mitius punitur. [...]

Item intellige etiam praedicta esse vera et locum habere in carcerato iuste et debite, secus autem puto esse in incarcerato indebite et iniuste, quia si talis iniuste et indebite carceratus frangit carceres et aufugit, non cadit in poena predictam ${ }^{123}$.

Anche la dottrina della ficta confessio viene in ogni caso circoscritta dal Marsili, a parere del quale

talis sic fugiens aperto carcere, non habetur pro confesso, secundum doctores: [...] regulariter fugiens de carcere habetur pro suspecto, non autem pro convicto. [...] Cynus in lege prima.C.de rap.virgi. [C. 9.13.1, I. raptores] dicit quod glossa in lege, eos.ff.de custo.reo. [D. 48.3.13, I. in eos] quae dicit quod fugiens effracto carcere, habetur pro confesso, debet intelligi hoc modo: videlicet, quia aut quis detinetur pro generali inquisitione: et tunc non habetur pro confesso, quia ficta confessio sicut vera debet cadere super certo et ideo debet crimen certum probari [...]. Aut detinetur pro inquisitone specialis criminis et tunc dicit quod aut fugit cum effractione vel conspiratione, et habet locum dicta lex eos, aut aliter, et tunc non habetur pro confesso: punitur tamen pro motu iudicis ${ }^{124}$.

\footnotetext{
${ }^{119}$ Angelus Aretinus, 1599, fol. 191.

${ }^{120}$ Cavina, 2013b.

${ }^{121}$ Sul genere letterario delle practicae criminali possono vedersi gli studi di Garlati, 2016; Miletti, 2015; Dezza, 2013, pp. 59-61.

122 Hippolitus de Marsiliis, 1551, foll. $81 v-85 v$.

${ }^{123}$ Hippolitus de Marsiliis, 1551, fol. 83v.

${ }^{124}$ Ivi, fol. 84r. Per il riferimento al commento di Cino si rimanda a Cynus Pistoriensis,
} 
Uno sguardo d'insieme all'insegnamento del Marsili porta a concludere come, contrariamente a quanto dichiarato espressamente in apertura con la lettura del De carceribus (a mente del quale parrebbe potersi concludere come una pena capitale avrebbe dovuto interessare chiunque, indistintamente, si rendesse irreperibile nel corso della propria prigionia in carcere), il giurista bolognese visualizzi l'ultimo supplizio quale sanzione per il fuggitivo nel solo caso di colui che attui la propria fuga effrangendo le mura del carcere o cospirando a ciò con gli altri detenuti; ciò, pur sempre, nella sola evenienza che ci si trovi nella fase dell'inquisitio specialis e a patto che il prigioniero sia stato originariamente ristretto «iuste et debite», locuzione chiarificata, forse un poco tautologicamente, allorché il Marsili dichiara che l'ingiustizia della carcerazione deriva dalla mancanza del rispetto dell'insieme di regole (sostanziali e procedurali) preposte a salvaguardia della libertà del detenendo ${ }^{125}$.

Riflessioni di segno consimile, tese cioè a scongiurare il più possibile l'inflizione di una pena capitale attraverso una chiara ed efficace enumerazione di tutte le circostanze incriminanti, si ritrovano anche in Egidio Bossi ${ }^{126}$ (1488-1546), ulteriormente calate, peraltro, nella prassi giudiziaria della prima età moderna: al titolo De carcere della sua Practica ${ }^{127}$, infatti, dopo aver ripreso punto per punto le tre "vie" trecentesche della pena capitale, della ficta confessio e del ricorso all'arbitrium iudicis (finendo per accedere all'interpretazione proposta da Alberico ${ }^{128}$ ), il senatore di Milano, confermato l'argine della iusta detentio ${ }^{129}$ e circoscritto spazialmente il campo dei loci dai quali l'evasione reca con sé la qualifica di fictus confessus ${ }^{130}$, eresse altre due barriere alla severità delle conseguenze desumibili dal dettato giustinianeo, la prima coi laterizi dello ius proprium e la seconda con la calce della prassi.

Habentur pro confessis et convictis [...]. Non tamen attentis statutis, quae communiter vigent, ubique locorum, ut nullus puniatur corporali poena, nisi lege mu-

\section{8, fol. $551 r$.}

${ }^{125}$ Si veda Hippolitus de Marsiliis, 1551, fol. 84r: «quando autem quid dicatur iniuste carceratus, vel quando iudex dicatur iniuste facere? Dicas quod tunc quando non fuit servatus ordo iuris».

${ }^{126}$ Sul penalista milanese si rimanda a di Renzo Villata, 2013 nonché ad Ead., 1996.

${ }^{127}$ Aegiudius Bossius, 1580, foll. 21-24. Alle conclusioni esposte in tale titolo rimanda peraltro lo stesso Egidio allorquando si trova ad affrontare, autonomamente, la questione «de effractoribus carcerum» (ivi, foll. 354-355).

${ }^{128}$ Aegiudius Bossius, 1580, fol. 22.

${ }^{129}$ Aegiudius Bossius, 1580, fol. 22: «est semper tamen intelligendum, ubi iuste carceratus detentus esset». II punto è nuovamente ripreso in ivi, fol. 355: "procedunt praedicta [...] si tamen iuste detentus cum legitimis indiciis».

${ }^{130}$ Aegiudius Bossius, 1580, fol. 21: «sed an habeatur pro confesso et convicto? Dic haberi lex in eos.ff.de custod.reor. [D. 48.3.13, I. in eos] [...] quod procedit, ut per eum, ubi effracto carcere aufugisset: item ubi ex publico carcere, secus si ex domo, vel civitate datis pro carcere, vel ex aliquo cubili non destinato pro carcere». 
nicipali caveatur: quia tunc posset capite naturali plecti talis effractor. [...] Et ad excludendum hanc poenam et praesumptionem, feci interdum capitulari, quod iudex talem male tractabat, adeo ut nisi aufugisset fame et frigore periisset ${ }^{131}$.

Rammentata la possibilità di procedere all'inflizione di una pena corporale nel solo caso la sanzione fosse espressamente autorizzata dagli statuti locali, è soprattutto sull'ultimo periodo che conviene soffermare l'attenzione: in esso, infatti, Bossi dichiara di essere stato costretto, di quando in quando, a far rilevare come alcuni giudici applicassero iniquamente le norme romanistiche, dovendo addirittura scongiurare l'eventualità che taluni fuggitivi fossero puniti quali evasi in seguito ad un evento effrattivo motivato esclusivamente dalla necessità di non morire di inedia o congelamento ${ }^{132}$.

Alcune interessanti considerazioni attinenti specialmente la consumazione del crimine d'evasione provengono invece dalla quotidianità dell'amministrazione della giustizia del Meridione grazie alla penna di Ludovico Carerio ${ }^{133}$, il quale, al Tractatus de indiciis della sua practica ${ }^{134}$, sembra richiamare (pur non esplicitamente) le conclusioni di Alberico da Rosciate quando espone che non vanno in alcun modo considerati quali ficti confessi quei detenuti che, «ut solet fieri multoties ${ }^{135}$, solo pianifichino la propria fuga o tentino di metterla in pratica senza riuscirci ${ }^{136}$.

Ancora più esplicita, in proposito, risulta essere la testimonianza di Giulio Claro $^{137}$ (1525-1575), allorché il consigliere d'Italia, alla quaestio XXI del Liber Quin$t_{u s}{ }^{138}$, tratta della rilevanza penale di qualsiasi evento di fuga, distinguendo, «ut habeas in materia fugae perfectam doctrinam ${ }^{139}$, tra il caso del soldato che si rifiuti di eseguire gli ordini e diserti il servizio ${ }^{140}$, il caso del reo che si allontani

\footnotetext{
${ }^{131}$ Aegiudius Bossius, 1580, fol. 22.

${ }^{132}$ In altro luogo del medesimo titolo, del resto, le ansie di Bossi per le condizioni dei detenuti rilucono di nuovo meritevolmente: "haec tantum volui dicere ad conclusione aliquorum malorum iudicum, qui nihil minus curant, quam ut in carceribus existentes dimittantur, ut vel foetidi intra carceres vitam finiant, dum iudices aliorum voluntati obsequuntur, vel fessi se componant dum illi ad propria utilitatem respiciunt» (Aegiudius Bossius, 1580, fol. 21).

${ }^{133}$ Sul giurista reggino si può vedere Malavasi, 2010.

${ }^{134}$ Ludovicus Carerius, 1562.

135 Ivi, fol. $52 r$.

${ }^{136}$ Ibidem: «non tamen habetur pro confesso absque conspiratione [...] et sequitur idem si tentabat aufugere, vel preparabat fugere tentando rumpere carceres».

${ }_{137}$ Per la vita e le opere del giurista alessandrino si rimanda a Massetto, 2017; Massetto, Parini, 2013.

${ }^{138}$ Iulius Clarus, 1574, foll. $77 r-83$ r.

139 Iulius Clarus, 1574, fol. 80r.

140 Ibidem: «debes scire, quod fuga tribus modis opponitur contra fugientem. Primo ut crimen, puta quando miles in bello aufugit».
} 
dalla scena del delitto appena perpetrato ${ }^{141} \mathrm{e}$, infine, quello che qui più interessa dell'evaso di prigionia.

Tertio autem modo opponitur fuga delinquenti tanquam confessio, puta quia reus e carceribus aufugerit, videtur enim fateri delictum de quo imputabantur, et ideo facit plenam probationem contra eum ${ }^{142}$.

Di primo acchito, potrebbe sembrare che Claro acceda all'opinione di coloro che propendono per l'applicazione della dottrina della ficta confessio, guardata come era, peraltro, da quella che il senatore di Milano esplicitamente definisce communis opinio doctorum ${ }^{143}$ :

talis enim, qui ex carceribus aufugit, habetur pro confesso, et convicto de eo crimine, de quo est imputatus, ut est textus in I.in eos.ff.decust.reorum [D. 48.3.13, I. in eos], secundum communem doctorum sententiam ${ }^{144}$.

Al rigore del dettato giustinianeo, cionondimeno, Claro oppone tutta la forza della sua esperienza di giudice ed il prestigio della giurisprudenza del Senato di Milano ${ }^{145}$, proclamando come

ideo potest de iuris rigore in poenam ordinariam condemnari, licet senatus hoc non observet, nisi contra contumaces, nam si quis post fugam captus sit, vel sponte revertatur, non solet propter fugam e carceribus factam illum condemnare, sed tantum gravius torquere ${ }^{146}$.

Sebbene, quindi, un'interpretazione rigorosa delle norme romanistiche potrebbe ben portare alla qualifica degli evasi quali ficti confessi - e qui non può non rimarcarsi come, nel discorso del Claro che qui si sta esaminando ${ }^{147}$, non figuri alcun riferimento alla possibilità di condannare all'ultimo supplizio i fuggitivi, essendo l'unica evenienza contemplata quella della fictio iuris -, la rilevanza di tale premessa viene quasi del tutto svuotata della sua portata autoritativa dinnanzi alla constatazione della prassi effettivamente propiziata dallo stylus del Senato,

141 Ibidem: «secundo opponitur fuga tanquam indicium, quando dicitur reus commisso aliquo delicto aufugisse, et a loco ipso delicti se absentem fecisse».

142 Iulius Clarus, 1574, fol. 80v.

${ }^{143}$ Su tale strumento concettuale si vedano Williams, 2019; Rossi, 2012b; di Renzo Villata, 2008; Rossi, 2001.

144 Iulius Clarus, 1574 , fol. $80 \mathrm{v}$.

${ }^{145}$ A proposito del cui stylus si rimanda a Monti, 2003 e Padoa Schioppa, di Renzo Villata, 2002.

146 Iulius Clarus, 1574 , fol. $80 \mathrm{v}$.

${ }^{147}$ L'unico, solitario riferimento alla pena capitale si ritrova, per vero, al punto nel quale Claro tratta degli evasi che riconquistino la libertà per vim: «scias etiam, quod si carcerati aufugiant nulla facta violentia, puta quia invenerint portam apertam negligentia commentariensis male carceres custodientis, non debent capite puniri» (Iulius Clarus, 1574, fol. 81r). 
secondo il quale colui che venga ricatturato o spontaneamente si riconsegni dopo la fuga non deve essere automaticamente qualificato quale colpevole del crimine per il quale era stato originariamente imprigionato ma, piuttosto, sottoposto a più rigorosa tortura.

Ulteriori limitazioni vengono poi allineate dal Claro, in vista di una circoscrizione sempre più estesa dell'utilizzo della ficta confessio, allorquando egli rammenta come la In eos non trovi applicazione a tutti quei casi nei quali il reo sia stato ristretto ingiustamente ${ }^{148}$.

Un secondo esempio della preponderanza ${ }^{149}$ che oramai, alla metà del secolo $\mathrm{XVI}$, la prassi senatoria milanese aveva saldamente assunto a discapito del diritto comune è, infine, offerto dal giurista alessandrino in tema di tentativo d'evasione:

item scias, quod si carcerati non aufugerint, sed tantummodo tentaverint fractis carceribus aufugere, Senatus non solet contra eos decernere, propter attentatam fugam, vel fracturam. Et ita observatum fuit in carceratis Laudae.10.Decembr.1543.[...]. Bene solet quandoque eos publice torqueri facere, et ita servari vidi in duobus, qui carcerem fregerant, ut aufugerent.16.Iul.1558. ${ }^{150}$

Anche alla luce delle risoluzioni adottate dal Senato nel dicembre del 1543 (a proposito di due fuggitivi dal carcere di Lodi) e nel luglio del 1558 (quando due evasi vennero puniti con la pubblica tortura), pare evidente come la gran parte delle disposizioni dell'utrumque ius in tema d'evasione dovesse oramai confrontarsi con uno ius proprium ${ }^{151}$ sempre più pressantemente in espansione: alle fonti giurisprudenziali, del resto, s'aggiungevano anche quelle locali, come testimoniato da un altro senatore di Milano, Jacopo Menochio ${ }^{152}$ (1532-1607), alcuni anni dopo nel suo trattato ${ }^{153}$ De arbitrariis iudicum.

Al casus $301^{154}$, infatti, il professore pavese propone un'elencazione di tutti i fatti a suo avviso penalmente rilevanti per il crimine d'evasione, principiando da coloro che approfittino di un «iam effractum carcerem atque ita apertum» ${ }^{155}$, proseguendo con chi invece applichi violenza a cose o persone nel tentativo di

\footnotetext{
148 Iulius Clarus, 1574, fol. 80v: «scias autem, quod haec conclusio, quod fuga e carceribus faciat contra reum plenam probationem delicti, intelligenda est ut procedat, quando talis carceratus fuit legitime detentus».

${ }^{149} \mathrm{Ma}$ anche, giova sottolinearlo, della fortuna delle intuizioni che, duecento anni prima, già Alberico da Rosciate aveva formulato a proposito della repressione del tentativo d'evasione.

150 Iulius Clarus, 1574, fol. 81r.

${ }^{151}$ In Donati, 2020a si contano alcuni esempi di statuti cittadini che ben prima del Cinquecento s'erano interessati alla materia carceraria.

${ }^{152}$ Per le cui opere e giorni si rimanda a Valsecchi, 2013c e Ead., 2009.

153 lacobus Menochius, 1576.

154 Ivi, foll. 253r-254r.

155 Ivi, fol. $253 r$.
} 
riguadagnare la libertà ${ }^{156}$ per concludere, infine, col caso dei detenuti che si giovino dell'effrazione messa in atto (con successo) da un altro detenuto ${ }^{157}$. In tutti e tre i punti, infatti, le "constitutiones Mediolani»" 158 vengono riguardate quale termine ultimo per l'applicazione delle pene approntate dallo ius commune, andando sia a confermare il dettato di questo sia ad essere interpretate alla di lui luce:

iudicis equidem arbitrio aliquando punitur; ut eo casu primo cum iam effractum carcerem atque ita apertum reperit; [...] haec sunt memoriae commendanda ad interpretationem constitutionum dominii Mediolani rubrica de poenis, capitulum si quis autem aliquid fecerit ${ }^{159}$, dum vult, hos effractores puniri poena a iure communi indictis. Intelliget iusdicens in casu isto esse tibi datum arbitrium indicendi hanc poenam.

Secundus est casus, quando carceratus fracto hostio, vel pariete fugit; tunc fuga operatur primo ut habeatur pro convicto et confesso de crimine [...]; secundo hic carceris effractor capitis poena punitur [...]. Ita erunt declarandae relatae constitutiones Mediolani dicto capitulo si quis autem. [...]

Extenditur secundo procedere in eo, qui est sub sola custodia, vel qui habet domum iusdicentis pro carcere; [...] quo circa licet constitutiones Mediolani in dicto capitulo si quis autem simpliciter de carcerato loquantur, attamen intelliguntur ut carcerati sint, et isti positi sub custodia, et intellige quando vi e custodum manibus aufugit, secus si illi negligentes permittebant illum vagari, et is arrepta occasione aufugit ${ }^{160}$.

Così, se nelle contrapposte evenienze del carcer apertus e dell'ostium fractum il diritto comune viene applicato in forza di un preciso richiamo del diritto di Milano, allorché Menochio tratta della possibilità di applicare anche a chi si trovi incarcerato solo cautelarmente nella struttura penitenziaria pubblica, il capitulum delle constitutiones va incontro ad una interpretazione estensiva della portata del lemma "carceribus»" ${ }^{161}$, recuperando peraltro le tralatizie cautele dello ius commune in tema di violenza usata contro i carcerieri e la di loro negligenza.

Oltre al variegato panorama delle norme locali ${ }^{162}$, però, Menochio prende in considerazione anche l'apporto della giurisprudenza, proponendo all'attenzione

\footnotetext{
156 Ibidem: "secundus est casus, quando carceratus fracto hostio, vel pariete fugit».

${ }^{157}$ lacobus Menochius, 1576, fol. 253v: «tertius est casus in solo effractore, qui vi fores carceris frangendo efficit, ut carcerati fugiant».

158 lacobus Menochius, 1576, fol. 253r.

159 II riferimento è qui, precisamente, a Constitutiones Mediolani, 1617, fol. 152: «si quis autem aliquid fecerit, propter quod ipse e carceribus evadat, puniatur poenis a iure communi statutis»

160 lacobus Menochius, 1576, foll. 253r-v.

${ }^{161}$ Constitutiones Mediolani, 1617, fol. 152.

162 In lacobus Menochius, 1576, fol. 253v si rammentano anche le disposizioni in uso «in regione Pedemontium», "Veronae», «Ferrariae», ad ulteriore conferma della vastità della cultura giuridica dell'autore.
} 
del suo lettore un caso che il professore pavese dichiara di aver visto trattare nei tribunali di Mondovì: dopo aver, infatti, dichiarato come il detenuto che si avvantaggi di quanto compiuto materialmente da un altro prigioniero (il Menochio propone l'esempio di chi abbia praticato dei fori attraverso le mura penitenziarie) vada punito con la stessa pena riservata al fuggitivo ${ }^{163}$ ed aver esteso tale sanzione a chiunque istighi, coadiuvi o consigli i detenuti all'indebita libertà ${ }^{164}$, il giurista pavese tramanda il fatto di alcuni carcerati, datisi con successo alla fuga, ai quali non si poté unire, a causa di una malattia debilitante che gli impedì di discendere l'asta con la quale gli altri compagni avevano colto la loro occasione, un solo prigioniero. Proprio su quest'ultimo si appuntò l'attenzione degli inquirenti, i quali sostenevano che, dal silenzio da questi serbato nel corso della fuga dei compenitenti, poteva affermarsi una sua responsabilità alla luce della In eos (D. 48.3.13). La difesa del prigioniero degente, invece, si basò sul timore inculcatogli dai compenitenti fuggitivi, i quali minacciavano di percuoterlo gravemente se questi avesse in alcun modo avvertito, con le proprie grida, le guardie carcerarie $^{165}$.

Pur non tramandando quale destino fosse poi toccato allo sventurato imputato di Mondovì, è noto che Menochio parteggiò per questi convintamente, invocando un'interpretazione restrittiva della portata semantica dell'elemento cospiratorio, secondo la quale per concorrere al disegno di un evento criminoso bisogna pur sempre poter prendere parte materialmente alla sua confezione (cosa che evidentemente, a causa della sua malattia, il detenuto di Mondovì non poteva fare $\left.^{166}\right)$.

Un'impressione generale del frastagliato e tutt'altro che armonico panorama nel quale trovava a muoversi la dottrina penalistica d'età moderna in tema d'evasione può essere rinvenuto, poi, esaminando le Varia rum quaestionum di Prospero Farinacci ${ }^{167}$ (1544-1618), nelle quali il giurista romano dedica un'intera

${ }^{163}$ lacobus Menochius, 1576, fol. 253v: «tertius est casus in solo effractore, qui vi fores carceris frangendo efficit, ut carcerati fugiant, ii eadem puniendi sunt poena, qua puniendi erant, qui aufugerunt».

164 Ibidem: «extenditur primo, hic casu ut locum etiam sibi vendicet in instigatore, fautore et consultore, qui suasit carcerato, ut fugeret».

165 Ibidem: «huc spectat quod aliquando in foro Montis regalis Pedemontinum vidi controversum. Aufugerant aliquando e carcere carcerati omnes uno excepto, qui propter corporis debilitatem non poterat hastam conscendere, et e perfracto pariete carcerem effugere. Illi delictum adscribebatur, quod aufugientibus consensisset, atque ita cum caeteris conspirasset, iuxta I.in eos.ff.de custod.reorum (D. 48.3.13), quoniam debebat clamare; ille respondebat, non potuisse cum esset perterritus illorum minis, qui eum acerrime verberassent».

166 Ibidem: «Ego iusta ratione contendebam illum non fuisse puniendum, cum conspirare cum caeteris non potuerit, est enim conspirare simul aspirare cum aliquem [...] sed hic ob impotentiam non poterat cum aliis pacisci».

167 Un profilo biobibliografico del causidico in Mazzacane, 2013. 
quaestio (la trentesima) al tema "carceres frangens et ab illis fugiens, quomodo, et quando puniatur ${ }^{168}$. II poderoso lavoro ricostruttivo del giureconsulto, che per la vastità delle argomentazioni citate appare ineguagliato dalla scienza coeva e richiamare, in quanto ad edificazione sistematica, le conclusioni di Alberico da Rosciate di due secoli precedenti, si perita anzitutto di distinguere tra le varie posizioni assunte dalla dottrina nel corso dei secoli, pur principiando il discorso con una ricognizione del dato testuale giustinianeo:

carcerum effractores et inde fugientes, quomodo puniantur, non adhuc bene a Doctoribus, quod viderim, explicatum credo; extat enim textus in I.1.in princ.ff.de effract. et expilat. [D. 47.18.1, I. de iis] [...]; extat et rursus textus in I.in eos.ff.de custod.reor. [D. 48.3.13, I. in eos] [...]. Hinc est, quod varii varia dixerunt, et adeo confuse Doctores in materia et in interpretatione dictarum legum loquuti sunt, ut quinam sit earundem legum verior intellectus, et quae sit poena carcerum effractoribus, vix dignosci possit, nisi res ab alto repetatur ${ }^{169}$.

A tal proposito, la più risalente opinione individuata dal Farinacci è quella di coloro che optarono per l'inflizione di una non meglio specificata pena capitale (aderendo il più strettamente possibile al dato testuale giustinianeo), alla quale seguì subito quella di chi interpretava tale sanzione nel significato della morte naturale e di chi, invece, raccomandava ${ }^{170}$ una pena sì capitale ma non quella, ultima, del patibolo ${ }^{171}$. Subito dopo, prosegue il causidico romano, fu il turno di quelle opinioni secondo le quali il nodo della punizione poteva essere risolto invocando la dottrina della ficta confessio, desunta da un'interpretazione estensiva

\footnotetext{
168 Prosperus Farinacius, 1589, foll. 292r-312r.

169 Prosperus Farinacius, 1589, fol. 293v.

170 Prosperus Farinacius, 1589, fol. 293v: «prima fuit scribentium opinio, eorum scilicet qui principaliter nisi sunt expressis verbis in dicta I.1.ff.de effracto. quod qui carcere effracto effugiunt, capitali poena plectantur; [...] secunda fuit opinio praecedentis declarativa, seu potius ampliativa, quod capitis poena de qua in dicta lege [...] sit mortis et ultimi supplicii [...]. Succedit opinio huic proxime contraria, quod imo ex quo quando lex facit mentionem de poena capitis, non intelligitur de poena mortis naturalis, sed de alia mitiori».

${ }^{171}$ Non si dimentichi, infatti, che con la locuzione "pena capitale», i giuristi si riferivano non solo alla pena di morte ma anche, in una scala di graduazione verso il basso, a quelle pene che privavano della libertà e della cittadinanza il reo (quale la damnatio in metallum) o solo della cittadinanza (quali la relegatio o la deportatio). Farinacci medesimo ne tratta in Prosperus Farinacius, 1589, fol. 172v («video ab omnibus communiter receptam poenarum distinctionem, quod aliquae sunt corporales, alique vero non corporales. Et ex corporalibus aliquae sunt capitales, aliquae autem non capitales. Item et capitalis poena tribus modis dicitur. Primo mortis naturalis et ultimi supplicii, quando scilicet et amissione vitae sequitur etiam amissio et libertatis et civitatis. Secundo mortis civilis, ut puta damnationis in metallum: ex qua licet quis vitam non amittat, amittit tamen et libertatem et civitatem. Tertio deportationis vel relegationis, ex qua licet quis nec vitam, nel libertatem amittat, amittit tamen civitatem »). Per l'origine classica di tutte le tipologie sanzionatorie testé citate si rimanda a Santalucia, 1998.
} 
della In eos (D. 48.3.13); anche contro questa scuola di pensiero, del resto, si allinearono coloro che, non trovando alcuna menzione più precisa circa la natura della pena da irrogare al fictus confessus, preferirono rimettere all'arbitrium del giudice (e quindi ad una pena in ogni caso più mite di quella capitale) la soluzione della questione ${ }^{172}$. Altri ancora, poi, vollero distinguere tra la pena da riservare a seguito di una fuga solo tentata e di una fuga riuscita ${ }^{173}$, mentre altri, infine, "minime respicientes ad incompatibilitatem poenarum ${ }^{174}$, proposero di considerare il fuggitivo quale reo confesso e, cumulativamente, meritevole della pena capitale.

Terminato di percorrere questa lunga galleria di opinioni e dottrine, Farinacci offre quindi la propria soluzione, proponendo di ridurre il vasto numero di soluzioni a solo due casi:

quid ergo dicendum in tanta opinionum varietate? Breviter pro vera resolutione ex praemissis duos principales casus fore distinguendos crediderim. Primus erit casus, quando effracto carcere carcerati iam aufugerunt, et isto casu recurrendum est ad dicta I.1.ff.de effractor. [D. 47.18.1, I. de iis], quae (ut ex eius lectura clare dignoscitur) proprie loquitur, quando fuga est sequuta, ut patet ex verbo eruperunt et ex verbo evaserint de quibus in textu, et ex quibus fugam iam sequta denotari negari non potest, de poena non est literaliter ambigendum, quia pariter in eadem lege aperte dicitur, quod est capitis, ut patet ibi, capite puniendus [...]. Sed de qua poena capitis intelligatur, an de poena mortis naturalis [...] an vero de poena capitis mitiori [...] crederem sine dubio intelligi debere non de morte naturali, sed de mitiori [...]. Nunquam enim memini me vidisse morti traditos huiusmodi effractores carcerum, etiam qui post fugam ad manus curiae pervenerint; sed bene eos, vel in delicto principali arctiori torturae submiserunt iudices, iuxta praedictam Mediolani, de qua supra, numero $12^{175}$, vel extra ordinem mitiori poena, quam

172 Prosperus Farinacius, 1589, fol. 294r-v: «subintrat opinio eorum, qui dixerunt poenam effractorum carcerum et ab illis fugientium, esse poenam confessatis criminis, pro quo erant carcerati; et propterea fore puniendos eadem poena, qua veniebat imponenda pro delicto, pro quo detenti erant [...]. Et praecedenti opinione prorsus contraria opinio fuit eorum, qui dixerunt, non esse verum quod textus in dicta l.in eos.ff.de custod.reo. exponi debeat, quod frangenti carceres imponenda sit poena confessati criminis: quia cum non exprimat poenam, dicendum est potius eam fore arbitrariam, et in occurrenti casu extra ordinem iudicis arbitrio, iuxta facti et personarum qualitatem esse imponendam».

173 Prosperus Farinacius, 1589, fol. 295v: «nonnullorum fuit opinio qui [...] dixerunt ad has leges concordans, quod textus in dicta I.in eos [D. 48.3.13], loquitur quando fuga est sequuta, et sic primo casu habeat locum poena delicti, pro quo effractor detinetur, cum habeatur pro confesso secundum communem intellectum, de quo supra; secundo autem casu habeat locum poena capitis». La paternità di tale distinzione è dal Farinacci esplicitamente riconosciuta ad «Albericus» (ibidem), al quale viene peraltro tributato il seguente, deferente riconoscimento: "talis videtur verus et germanus intellectus illius legis» (ibidem).

${ }^{174}$ Prosperus Farinacius, 1589, fol. $295 \mathrm{v}$.

175 II riferimento è qui all'insegnamento del Claro, espressamente rievocato alla mede- 
mortis mulctarunt, iuxta facti et personarum qualitatem et sic illam capitis poenam mitiorem, de qua in dicta I.1.ff.de effract. ut plurimum iudices in arbitrariam apud nos commutare solent ${ }^{176}[\ldots]$.

La prima eventualità esaminata dal giureconsulto romano è dunque quella di chi riesca a portare a felice esito la propria fuga: tale fatto è dal Farinacci sussunto entro la fattispecie edificata con la lex De iis (D. 47.18.1), la quale, però, non esprimendo la specie della pena capitale comminanda, autorizzerebbe l'interprete a ripiegare su una pena più mite (anche nel genere). È proprio a questo punto, del resto, che il causidico mette in campo la propria esperienza di conoscitore della prassi delle corti del suo tempo, sottolineando come non gli consti di alcun caso nel quale i fuggitivi siano stati mandati a morte in ragione della sola fuga dal carcere. Piuttosto, soggiunge il Farinacci invocando anche la prassi del Senato di Milano tramandata da Giulio Claro, i giudici sono soliti o sottoporre a più severa tortura i fuggitivi ${ }^{177} \mathrm{o}$ ad irrogare loro una sanzione non capitale ${ }^{178}$, essendo oramai occorso per praxim il mutamento qualitativo da pena capitale ad arbitraria.

Secundus erit casus, quando carcerati nondum aufugerunt, sed vel effracto carcere volentes aufugere, vel in ipsa fuga, vel nondum perfecta fractura fuerunt praeventi, et sic non potuerunt, vel etiam poenitentes propter rei difficultatem, aut timore poenae, vel ex alia causa noluerunt aufugere: et isti sunt proprii termini I.in eos.ff.de custo.reo. [D. 48.3.13]; [...] et iste casu non crederem indistincte et uniformiter semper fore imponendam poena delicti, pro quo detinebatur tanquam illus fuerint confessi [...]; sed bene crederem imponi posse aliam poenam arbitrariam, modo graviorem et modo leviorem, non habito respectu ad delictum, pro

sima quaestio in Prosperus Farinacius, 1589, fol. 295r: «Clarus in pract.§.si.q.21.d.versi. tertio autem modo, post principium bene etiam animadvertit quod textus in dicta I.in eos, non probat communem intellectum, quod scilicet ex carcere fracto aufugientes habeantur pro confessis; et propterea quod Senatus non observat dictum communem intellectum: quia si quis post fugam captus sit, vel sponte revertatur, non solet propter fugam a carceribus factam illum condemnare, sed tantum gravius torquere». L'assoluta preponderanza dell'arbitrium giudiziale in proposito è del resto riconosciuta subito dopo, allorché il Farinacci commenta lo stylus del Senato milanese: «quae quidem observantia est multum conformis cum opinione supra relata eorum, qui voluerunt isto casu esse poenam arbitrariam, quasi quod iudex propter arbitrium sibi a iure in hoc concessu, possit tales effractores eos et acrius torquere super delicto, pro quo detinetur, tamquam magis suspectos ex fuga et ex fractura et etiam si sibi videtur eosdem publice torqueri facere» (ibidem).

176 Prosperus Farinacius, 1589, fol. 295v-296r.

${ }^{177}$ Circostanza tutt'altro che invidiabile se lo stesso Farinacci, poco dopo, si sente in dovere di sottolineare come «illam acriorem torturam, quae (ut dicunt Doctores) maior poena est quam utriusque manus abscissio» (Prosperus Farinacius, 1589, fol. 296r).

178 Tra le quali, lo stesso Farinacci ricomprese l'«amputationis membri vel manus» (Prosperus Farinacius, 1589, fol. 175v), la fustigazione, la berlina o la tortura ad poenam (ivi, foll. $176 r-v)$. 
quo effractores detinentur sed ad fracturae et conspiratorum qualitatem [...]. Et ad sic dicendum ea potissimum moveor ratione [...] quod textus in d.I.in eos., dicit simpliciter huiusmodi effractores fore puniendos: sed qua poena, non exprimit, unde censetur remissa arbitrio iudicis ${ }^{179}$.

II momento proprio di applicazione della In eos (D. 48.3.13), invece, sarebbe quello della punizione di coloro che hanno solo tentato di evadere dalla prigionia: anche qui, cionondimeno, Farinacci esclude che la pena da applicare sia quella comminata dal testo giustinianeo, preferendo ancora una volta rimettere la soluzione ai poteri arbitrari del giudice, il quale dovrà graduare la sanzione avendo in mente anzitutto le circostanze della fuga e non del delitto per il quale i detenuti erano stati originariamente imprigionati.

Gli argomenti dispiegati dal Farinacci per sostenere tale interpretazione sono due: anzitutto, la compilazione giustinianea, non specificando quale pena fosse da irrogare ai tentati fuggitivi, avrebbe autorizzato il giudice a colmare tale lacuna coi propri, vasti poteri discretivi ${ }^{180}$; in secondo luogo, si dilunga, con dovizia di esempi, a spiegare il giurista ${ }^{181}$, gli esiti di una generale applicazione di codesta interpretazione letterale sarebbero assurdi. Si ponga mente, infatti, al caso di chi si trovi detenuto - e qui Farinacci evoca quasi una sorta di figura archetipica, dalle tinte quasi picaresche, dell'ospite assiduo delle carceri romane - per gioco, rissa o altro delitto minore e, una volta rinchiuso in cella, cospiri con gli altri detenuti ad infrangere le mura penitenziarie: certo, prosegue Farinacci, la sola pena riservata ai giocatori, ai rissosi e ad altri colpevoli di delitti minori sarebbe ben poca cosa per chi ha cospirato a violare la sicurezza delle pubbliche carceri. Se ci si finge, però, il caso di un accusato di omicidio (ossia di un reato per il quale il patibolo era previsto a livello edittale) che tenga la medesima condotta, apparirà come manifestamente iniqua l'immediata ed automatica inflizione della pena di morte che a questo andrebbe irrogata qualora si accedesse all'interpretazione letterale della In eos (D. 48.3.13). Molto meglio, nell'opinione del Farinacci, rimettere la commisurazione della gravità del fatto evasivo al prudente apprezzamento del

\footnotetext{
${ }^{179}$ Prosperus Farinacius, 1589, fol. 296r.

180 Il fenomeno, tuttaltro che ignoto alla storiografia giuridica, è stato studiato in Meccarelli, 2009 oltre che in Id., 1998.

${ }^{181}$ Prosperus Farinacius, 1589, fol. 296r: «item moveor: fingamus quem detineri pro pugnis, pro ludo, pro lumine, vel pro aliis delictis levibus, prout saepissime in carceribus Urbis tales sic detenti reperiuntur, et quod conspirando cum aliis carceres fregerit: non ne erit absurdum dicere illum sic carcerum effractorem, et cum aliis conspirantem, non alia poena afficere quam pro pugnis, pro ludo, pro lumine et similibus. Crederem certe istius audaciam acrius reprimendam. Fingamus e contra quem detineri pro homicidio, quod mortis poenam mereatur, ut sanguinem suum redimat, quaerit aufugere. Praeventus in fractura, vel fuga, non potuit: erit ne dicendum, hunc statim esse morti tradendum tanquam confessum? Certe non, et in practica nunquam vidi talem rigorem de iure sine Principis iussu servari et Principem hoc iussisse, haud certe testari possum».
} 
giudice, che potrà soppesare più chirurgicamente ogni elemento circostanziale (come peraltro spesso accadde di vedere osservato al giurista medesimo) ${ }^{182}$.

Conscio, e non senza una certa qual personale soddisfazione, della grandiosità dell'edificio scientifico appena completato ${ }^{183}$, Farinacci serba dunque pochi dubbi sulla natura della sanzione più opportuna da riservare agli evasi:

regula igitur ex praemissis firma remanet, quod carcerum effractores arbitraria poena puniendi sunt, sive aufugerint, sive non: sed si non aufugerunt, mitius puniendi quam si aufugissent ${ }^{184}$.

Se, del resto, si volge ora lo sguardo ad alcuni prontuari penalistici ad uso dei canonisti ${ }^{185}$, è anzitutto la Canonica criminalis practica di Pietro Follerio ${ }^{186}$ (1518?-1588?), tra quelle consultate ${ }^{187}$, a prendere in esame la questione: ivi, al dodicesimo capitolo, il giurista sanseverinese, piuttosto stringatamente ${ }^{188}$, sentenzia senza tentennamenti di sorta come i chierici imprigionati che effrangano le mura del carcere e si diano alla fuga possano ${ }^{189}$ essere, a mente del dictum che s'è già avuto modo di citare del Panormitano, privati della propria dignità clericale e, stante la loro incorreggibilità, consegnati per l'esecuzione al braccio secolare ${ }^{190}$.

Informate a più miti ed aggiornati criteri, invece, appaiono le più tarde conclu-

182 Prosperus Farinacius, 1589, fol. 296r: «rursus et moveor, quia effractores carcerum puniuntur propter fracturam, et non propter delictum, pro quo detinentur, unde poena commensuranda est fracturae, non autem delicto, et sic indubitanter credo poenam isto casu esse arbitrariam citra mortem, et ita saepius servatum vidi, et si effractores erunt viles personae, poterunt si ita iudici visum fuerit, in publico pro poena torqueri facere, iuxta tradita per Clarum».

${ }^{183}$ Prosperus Farinacius, 1589, fol. 296v: «et ita credo in praemissa disputatione esse puram veritatem, quam (ni fallor) nemo hucusque sic distincte in tanta Doctorum varietate explicavit».

${ }^{184}$ Prosperus Farinacius, 1589, fol. $296 \mathrm{v}$.

185 Il riferimento è, sul punto, a Dezza, 2016.

${ }^{186}$ Per la vita e le opere del giurista si rimanda a Birocchi, Miletti, 2013.

${ }^{187}$ Altre due celebri practicae che si è avuto modo di esaminare (loannes Bernardus Diaz de Luco, 1614; Ignatius Lopez de Salcedo, 1666), peraltro, non paiono dedicare alla questione una specifica trattazione.

${ }^{188}$ Un avverbio che pare di potersi utilizzare specialmente alla luce delle ben più dense pagine dedicate alla questione dal medesimo autore nella sua Practica criminalis (si veda Petrus Follerius, 1556, foll. 373-376), ove, ai fini della sussunzione della condotta dell'evaso nella oramai familiare qualifica di fictus confessus, sono allineati ben ventidue requisiti.

${ }^{189} \mathrm{E}$ qui, forse, è comunque il caso di significare tutta la portata semantica, solamente potenziale, del verbo utilizzato dal Follerio, peraltro ripreso in toto dal Panormitano.

190 Petrus Follerius, 1561, fol. 169: «quid enim si clerici carcerati effregerint carceres, et aufugerunt, qua poena puniri debeant? Dominus Abbas in c.a nobis.de aposta. in fine, dicit quod potest procedi ad depositionem, et data incorregibilitate, ad traditionem curiae seculari». 
sioni espresse dal minorita osservante Francesco Pitigiani da Arezzo ${ }^{191}(† 1616)$, secondo il quale, in una trattazione che si rifà esplicitamente a Giulio Claro e nonostante l'autore concorra alla teoria della ficta confessio, il fuggitivo che effranga le mura del carcere nel quale era stato «legitime detentus»" ${ }^{192}$ non deve essere qualificato come colpevole ma solo torturato più rigorosamente ${ }^{193}$.

Un ulteriore segnacolo di quello che può apparire come un incipiente ma faticoso superamento di rigide interpretazioni in tema d'evasione anche nel contesto del diritto canonico può essere rinvenuto se si volge lo sguardo alla giurisdizione inquisitoriale romana: anche per queste plaghe del diritto, infatti, è dato, nel corso del Cinquecento, rinvenire un mutamento nella lettura dottrinale delle norme contro i fuggitivi.

Se, infatti, allorché Camillo Campeggi ${ }^{194}(† 1569)$, nella seconda metà del XVI secolo, ripropose all'attenzione del mercato librario italiano il trattato trecentesco sulle eresie di Zanchino Ugolini, corredandolo di proprie additiones, la questione dell'evasione parve doversi risolvere conformemente a quanto già proposto dall'Eymerich due secoli prima ${ }^{195}$, già Diego de Simancas ${ }^{196}(† 1583)$, nelle sue Catholicae institutiones ${ }^{197}$, aveva dato voce ad alcuni seri dubbi circa la bontà delle teorie di chi vedeva negli imprigionati per eresia che si davano alla fuga degli eretici confessi. Anzitutto, il vescovo spagnolo si era peritato di qualificare come alquanto semplicistiche codeste teorie ${ }^{198}$, rammentando semmai come

ego vero ab illorum opinatione vehementer dissentio quia si, qui e carcere fugit, impoenitens est, non relapsus, ideoque si poenitere velit, audiendus et re-

\footnotetext{
${ }^{191}$ Sul quale può ora vedersi Lagioia, 2017.

${ }^{192}$ Franciscus de Pitigianis OFM, 1617, fol. 208.

${ }_{193}$ Ibidem: «talis fuga facit contra eum plenam probationem, quia fateri videtur delictum, de quo imputabatur; atque ita habetur pro confesso, et convicto, quod si post fugam capiatur, vel sponte revertatur, non solet per sola fugam de carceribus factam condemnari, sed tantum gravius torqueri; sed si statim reverteretur, non esset tamquam fugitivus, et fractor carceris puniendus».

${ }^{194}$ Sul domenicano pavese e sull'opera sua un primo approfondimento in Donati, 2021, pp. 380-404.

195 Zanchinus Ugolinus, Camillus Campegius O.P., 1579, foll. 74-75: «quod autem ille, qui, a loco sibi pro poenitentia assignato, fugit, pro haeretico damnari possit, confirmat idem Felynus in dicto c.excommunicamus. et allegat lohannes Andreae in c.ut commissi.eod. lib.6. dicitque talem fugientem ex hoc solo haberi pro convicto, ac si in haeresim relapsus esset, et quod absque ulla audientia seculari brachio tradendus est. [...] Rursus adde, in eadem poenam illum incidere, qui aliam impositam sibi ab inquisitore poenitentiam post abiurationem non adimplevit».

196 Pastore, 2010.

197 lacobus Simancae, 1584.

198 lacobus Simancae, 1584, fol. 137v: «vulgo autem dici solet, fugiens a carcere pro confesso habetur, et crimen pro quo vinctus erat, fateri videtur, sed id iure communi mihi non probatur».
} 
cipiendus est [...] Ille qui fugit, nullam haeresim fuga ipsa commitit, nec iudices praesumere, aut fingere debent quempiam esse relapsum, quem lex nominatim relapsum esse non dicit ${ }^{199}$.

Le parole del Simancas sono del resto rimarchevoli - specie per la delicatezza della materia nella quale è dato trovarle calate, caratterizzata da molti e penetranti specialia ${ }^{200}$ - anche per lo scoperto, esplicito riferimento al concetto di iusta detentio, del quale si è già avuto modo di discorrere:

non solum is, qui iniuste damnatus est, potest e carcere licite fugere, sed etiam ille qui ad mortis poenam iuste condemnatur a iudice, quia nemo tenetur id facere, ex quo mors consequatur, quod faceret vinctus, si maneret in carcere, cum fugere posset, tametsi aliud longa, et eleganti disputationem defendat Socrates apud Platone in Critone, non tamen debet resistere iudici iuste sententiam exequenti. Et haec est recepta sententia theologorum, ut [...] Thomas 2.2.q.69201.

Anche solo uno sguardo cursorio alle diverse conclusioni sinora riportate restituisce un solido punto di partenza per poter affermare che, anche in ambito canonistico ${ }^{202}$ - che già in epoca medievale risultava caratterizzato da una vaga, minore severità, perlomeno nelle proposte interpretative, rispetto alla coeva dottrina civilistica -, il vento dell'esegesi stava muovendosi nel senso di un graduale superamento di alcune certo efficaci ma non per questo meno problematiche deduzioni gnoseologiche; da questo punto di vista, specialmente, le parole del Simancas ${ }^{203}$ risultano quanto mai opportune: infatti, cosa conferisce, ex se, l'evento fuga alla conoscenza del giudice relativamente al delitto per il quale l'evaso era stato incarcerato? L'evasione - per tornare all'argomentare delle Catholicae institutiones - è forse un'eresia? E, allargando il campo al diritto canonico tutto, verrebbe da domandarsi: in base a quale criterio - la risposta del Simancas è chiara: "vulgo dici solet» ${ }^{204}$ - può ragionevolmente dedursi che la fuga di alcuno dal carcere equivalga ad un'ammissione di colpevolezza? A maggior ragione, conclude il Simancas, se anche i teologi, e Tommaso su tutti, hanno già concordato che non solo chi è stato ingiustamente imprigionato può fuggire ma anche che

\footnotetext{
199 lacobus Simancae, 1584, fol. 137v.

200 Santangelo, 2017.

201 lacobus Simancae, 1584, fol. 137v.

${ }^{202}$ Un ulteriore esempio a sostegno di quanto si sta per affermare si troverà, sempre per l'ambito inquisitoriale, al prossimo paragrafo.

${ }^{203}$ Alle quali fanno armonica eco quelle di Francisco Peña nella riedizione commentata del Directorium dell'Eymerich in Eymerich, Peña, 1587, fol. 644: «contraria sententia verior et benignior est, videlicet, fugientes e carceribus praedicto modo impoenitentes quidem esse censendos, at nullo modo relapsos, ita Simancas et vere de catho.insti.tit.16. nu.25. Nec desunt rationes, quia non est relapsus nisi qui in haeresim labitur, at qui fugit e carcere, nulla haresim fuga commitit». Sull'officiale spagnolo della Congregazione del Sant'Uffizio il rimando è a Lavenia, 2010.

204 lacobus Simancae, 1584, fol. 137v.
} 
colui che sia stato invece giustamente condannato non è tenuto a subire passivamente - purché non provochi mali ad altri con la propria fuga - l'irrogazione della pena di morte?

\subsection{Alcuni casi concreti: consilia e decisiones}

Prima di cimentarsi nel tentativo di intessere alcune conclusioni, necessariamente preliminari, sul tema prescelto, non pare metodologicamente scorretto proporre all'attenzione del lettore alcuni episodi coevi alle riflessioni delle quali si è finora discorso, traendoli tanto dalla letteratura consiliare - antico genere letterario nel quale i giuristi si erano cimentati ininterrottamente a partire dal Medioevo ${ }^{205}$ - quanto dalle raccolte di decisiones giurisprudenziali - le quali, a partire dalla prima età moderna, cominciarono a circolare a stampa per tutte le biblioteche d'Europa ${ }^{206}$ - : si avrà così modo di far intravedere, attraverso episodi ${ }^{207}$ sì incastonati in scritti di esperti giuristi ma pur sempre provenienti dal magma ribollente della pratica quotidiana delle corti, le modalità con le quali i principii dei quali si è sopra discorso ebbero l'occasione di confrontarsi con il banco di prova della realtà.

Nel ventesimo giorno di un febbraio della seconda metà del XV secolo ${ }^{208}$, in Bologna, "Antonius Franciscus de Fontana ${ }^{209}$ confessa, sotto tortura, di essersi introdotto in casa di «Dominico de Gargotis» ${ }^{210}$; di aver rapito la di lui figlia, Domenica; di averla tenuta sequestrata presso la casa di un amico e, a completamento del fosco quadro ${ }^{211}$, di aver fatto tutto ciò «eam carnaliter cognoscendo et

\footnotetext{
${ }^{205}$ Un'aggiornata analisi non solo a proposito del genere letterario in sé ma anche dell'evoluzione interpretativa che la storiografia giuridica italiana gli ha dedicato può rinvenirsi, assieme alle opportune notazioni bibliografiche, in Nobile Mattei, 2018.

${ }^{206}$ Wijffels, van Rhee, Alvazzi del Frate, 2013; Ascheri, 2012; Sbriccoli, Bettoni, 1993; Ascheri, 1989.

${ }^{207}$ Per alcuni episodi tratti invece da fonti d'archivio si può vedere Pedrini, 2018.

${ }^{208}$ Quale termine post quem per la datazione del consilium sull'evasione (in Alexander Tartagnus, 1590 a, foll. $125 \mathrm{v}-126 \mathrm{v}$ ) può proporsi con una certa sicurezza il 1451, anno del conferimento della cittadinanza bolognese al Tartagni; al termine del consilium ove vengono narrati più diffusamente i fatti addebitati ad Antonio Francesco Fontana (Alexander Tartagnus, $1590 \mathrm{~b}$, foll. $2 r-4 r$ ), infatti, il giurista così sottoscrive la propria consulenza «ita dico et consulo ego Alexander bononiensis» (Alexander Tartagnus, 1590b, fol. 4r).

${ }^{209}$ Alexander Tartagnus, 1590b, fol. $2 r$.

${ }^{210}$ Ibidem.

${ }^{211}$ Al quale sembra di dover aggiungere lo stupro della giovane, perlomeno stando a quanto confessato dallo stesso Antonio sotto tortura (e sebbene egli lamentasse il consenso previo della donna): "die 26 et die 28 eiusdem mensis confessus fuerit rapuisse dictam Dominicam et ipsam quod voluit dixisse, et retinuisse ipsam carnaliter cognoscendo modo, et forma in iniquisione [sic] contentis, de voluntate tamen dictae Dominicae, absque voluntate patris, matris, fratrum dictae Dominicae, et quod antequam desponsaret eam, semel cognovit carnaliter in domo Ioannis Tamburini» (Alexander Tartagnus,
} 
habendo in uxorem ${ }^{212}$.

A risollevare le sorti della difesa di Antonio venne chiamato Alessandro Tartagni $^{213}$ (1424-1477), nella cui vasta raccolta di consilia sono conservati almeno due pareri riguardanti questa torbida vicenda. Quello che qui interessa maggiormente è il più contenuto "CXLIIII»" ${ }^{214}$, nel quale il giurista bolognese - dopo aver concluso, nel primo consulto, come il suo assistito andasse assolto da qualsivoglia imputazione, essendo stata ogni confessione a suo carica estorta col ricorso a quaestiones del tutto illegittime ed irrituali, o, tuttalpiù, condannato al pagamento di una somma da destinare al padre di Domenica a titolo di risarcimento ${ }^{215}$ affronta il problema del trattamento da riservare al suo cliente a seguito di una fuga da lui messa in atto "contra voluntatem custodis carceris»" ${ }^{216} \mathrm{e}$, più in particolare, se Antonio andasse considerato quale reo confesso per i crimini ascrittigli, specialmente alla luce di alcune previsioni statutarie che avevano recepito la oramai familiare dottrina della ficta confessio ${ }^{217}$.

A sostegno delle ragioni del proprio assistito, Tartagni dispiegò apertamente tutta la forza del concetto di actus iustus, sostenendo come l'evasione di Antonio fosse pienamente giustificata alla luce dell'illegittimità della tortura subita ${ }^{218}$ : questa, infatti, sarebbe avvenuta non solo in spregio ai termini concessi all'imputato per presentare le proprie difese ma anche senza la presenza degli indizi sufficienti per procedervi ${ }^{219}$, di modo tale che «licuit dominus Antonius resistere

1590b, fol. 2r).

212 Ibidem.

213 Padovani, 2019; Id., 2013.

${ }^{214}$ Alexander Tartagnus, 1590a, foll. 126r.

${ }^{215}$ Ibidem: "post redditum primum consilium in causa Antonii de Fontana, in quo conclusi eum fore totaliter absolvendum, praesertim stantibus nonnullis confessionibus suis occasione torturae indebite et illegitime illatae, et eo casu quo dici potuisset confessionem, vel confessiones esse validas, conclusi eum esse puniendum et condemnandum ad poenam mille librarum applicandam patri dictae Dominicae».

216 Ibidem.

${ }^{217}$ Ibidem: «suborta est dubitatio, attento quod dictus Antonius, ut dicit, evasit de carcere et aufugit contra voluntatem custodis carceris, debet haberi pro confesso pro omnibus quae continebantur in inquisitione, maxime stante statuto posito sub rubrica de poena custodum carcerum, in vericolo carcerati vero fugientes et c. ibi dum dicit: "si vero pro crimine, quod eis adscriptum esset, pro confessis habeantur; et sic de tali crimine condemnentur"».

${ }^{218}$ Alexander Tartagnus, 1590a, foll. 126r: «respondeo, quod dictus Antonius ante dictam fugam fuit illegitime et indebite tortus per dominum Vexilliferum iustitiae una cum tribus ex dominis Antianis, et praesente domino Potestate, et aliquibus suis iudicibus et militibus».

${ }^{219}$ Alexander Tartagnus, 1590a, foll. 126r: «sed contra dictum Antonium processum fuerat ad actum torturae evidenter iniuste, scilicet intra terminum datum ad purgandum indicia. Et ideo non praecedentibus legitimis indiciis». Per una teoria delle prove in epoca di diritto comune si rimanda a Rosoni, 1995. 
tali iniustitiae evadendo de carceribus, ut fecit» ${ }^{220}$. L'ingiustizia nell'adozione dello strumento probatorio, del resto, non venne dal giurista fondata unicamente su ragioni formali ma anche sulla constatazione, di natura sostanziale, secondo la quale la tortura, una volta portata a compimento, rappresenta un che di irreparabile, anche in sede di sindacato, autorizzando, conseguentemente, l'imputato che vi venga ingiustamente sottoposto a resistere al magistrato procedente ${ }^{221}$.

A rinsaldare ulteriormente tale concetto, il Tartagni invocò l'auctoritas di Bartolo, il quale già aveva insegnato come, qualora i magistrati comunali detengano ingiustamente qualcuno, questi abbia più che il diritto di darsi alla fuga e di non essere sottoposto, in caso di successiva cattura, ad alcuna sanzione: orbene, soggiunge il giurista bolognese, se ciò è vero in presenza di una cattura ingiusta, tanto più vero sarà allorquando il prigioniero sia stato illegittimamente torturato, essendo il rigoroso esame atto ben più gravoso di qualsivoglia detenzione ${ }^{222}$. All'obiezione, del resto, secondo la quale lo statuto e financo la littera del Digesto avrebbero riguardato il fuggitivo quale reo confesso, il Tartagni oppone la propria interpretazione additiva, sottolineando come il disposto statutario vada comunque letto alla luce di un criterio sostanziale di giustizia: richiamando qui, inoltre, l'interpretatio baldesca (e non senza una punta di tralatizio antisemitismo), il giurista rammenta come "statuta non sunt iudaice intelligenda» ${ }^{223}$, ovverosia come non vadano interpretati secondo il loro significato deteriore, pena il rinvenimento di soluzioni patentemente inique (come sarebbe nel caso della punizione perfettamente conforme, stricto sensu, a qualsiasi norma che reprima l'omicidio - di chi provochi la morte di alcuno per legittima difesa ${ }^{224}$ ).

Una valutazione, del resto, pienamente rispondente alle disposizioni statutarie

${ }^{220}$ Alexander Tartagnus, 1590a, foll. 126r.

${ }^{221}$ Alexander Tartagnus, 1590a, foll. 126r: «modo sic magistratui, vel magistratibus iniuste facientibus licitum est etiam de facto resistere [...]; licitum est etiam privato resistere iudici [...], quod quando iudex ingiuste agit in ferendo gravamen, quod reparari non potest in syndicatu, ut est tortura, et alia similia, tunc licitum est de facto resistere».

${ }^{222}$ Alexander Tartagnus, 1590a, foll. 126r: «ad praedicat verba facit, quod notat Bartolus in I.vis eius.C.de proba. [C. 4.19.15] ubi per illum textum voluit, quod si quis detineatur a Potestate vel Capitaneo iniuste, et ipse aufugiens tenetur, sed non est dubium, quod maius gravamen est, et minus reparabile, quando quis iniuste torquetur, quod quando quis iniuste carceratur».

${ }^{223}$ Alexander Tartagnus, 1590a, foll. 126r: «nam ut dixit Baldus [...] statuta non sunt iudaice intelligenda, adeo quod contineant pravum sensum».

${ }^{224}$ Alexander Tartagnus, 1590a, foll. 126r: «non obstante quod statutum dicat, quod tales evadentes habeantur pro confessis de crimine, quod eis ascriptum esset; sicut etiam legitur et notatur in I.in eos.ff.de custo.reo. [D. 48.3.13]. Quia respondeo, quod statutum intelligitur, nisi iustam habuerit causam aufugiendi et equam: quia cessabit dispositio statuti; [...] quod licet statutum disponat, quod faciens homicidium decapitetur [...] non debet intelligi in eo, qui ad sui defensionem occiderit, si habuerit iustam causam occidendi». 
è offerta da Bartolomeo Bertazzoli225 $(+1588)$ nel caso di Paolo Polletto, il quale aveva fornito al compagno di prigionia, Francesco Zampelloni, lima e scalpello perché potesse scampare alla condanna a morte già irrogatagli per omicidio ${ }^{226}$. Il destino del Polletto - intorno al cui reato in ragione del quale era stato originariamente imprigionato il Bertazzoli tace nei suoi Consilia - si intrecciò quindi, a titolo di complicità, con quello della fuga di Zampelloni, la quale si interruppe allo stadio di tentativo mero, non essendo questi nemmeno riuscito, nonostante gli strumenti a disposizione, ad effrangere le mura del carcere di Mirandola presso il quale era detenuto: per ciò che concerne la punizione del correo nell'evasione, infatti, gli statuti cittadini ${ }^{227}$ stabilivano che al condannato a morte che aveva violato la sorveglianza della prigione ed era riuscito ad evadere toccasse non solo l'irrogazione dell'ultimo supplizio ma anche una ulteriore e previa sanzione, rimessa all'arbitrio dei magistrati procedenti e presumibilmente di natura esemplare, che potesse riuscire didascalica ai consociati che vi avrebbero assistito, secondo una chiara impostazione general preventiva ${ }^{228}$; nel caso ${ }^{229}$, invece, il prigioniero non riuscisse a portare a compimento la fuga (sia perché ricatturato, pur sempre entro le mura della prigione, dopo l'avvenuta effrazione, sia perché non gli era stato possibile portare a termine nemmeno quest'ultima - come nel caso dello Zampelloni-), gli statuti prevedevano, quale pena edittale, due colpi di "squasso» ${ }^{230}$, ossia, come spiega più perspicuamente poche righe dopo lo stesso Bertazzoli, la sottoposizione alla tortura di due colpi di corda ${ }^{231}$.

La rilevanza del trattamento sanzionatorio riservato all'evaso venne in rilievo nel caso del Polletto - e in tal senso fu certo una fortuna per lui che lo Zampelloni non riuscisse a portare a termine la propria evasione -, giacché l'ultimo capitola-

\footnotetext{
${ }^{225}$ Ascari, 1967.

${ }^{226}$ Bartholomaeus Bertazzolius, 1602, fol. 77r: «nunc videndum est qua poena veniret puniendus Franciscus Zampellonus, bannitus et condemnatus ad mortem, qui recepit a Paulo Polleto limam et celum, seu scarpellum quibus potest carcerem frangere et evadere, ex quo non potuit ipsum frangere et fugere, ut exinde cognoscamus qua poena iste Polletus teneatur».

${ }^{227}$ Si vedano gli Statuta Mirandulae, 1386, pp. 117-118 per l'edizione critica della rubrica "De poena carceratorum frangentium carceres".

${ }^{228}$ Bartholomaeus Bertazzolius, 1602, fol. 77r: «per statutum Mirandulae sub rubrica de poenis carceratorum frangentium carceres dispositum est quod carceratus pro delicto frangens carcerem, et fugiens, si veniret puniendus, condemnandus poena mortis, ante ipsam poena mortis acrius puniatur ad voluntatem Dominorum, et demum ad mortem, quam merebatur, puniatur et condemnatur».

${ }^{229}$ Bartholomaeus Bertazzolius, 1602, fol. 77r: «si autem carceres fregerit, vel frangere incoeperit, et extra dictos carceres non aufugerit, tunc ultra condemnationem et poenam, qua dictus carceratus venit condemnandus, et puniendus pro ipso delicto delicto, vel maleficio pro quo erat carceratus, bis cum quasso torqueatur».

${ }^{230}$ Statuta Mirandulae, 1386, p. 118.

${ }^{231}$ Bartholomaeus Bertaazzolius, 1602, fol. 77r: «tenetur ea poena duorum ictuum funis».
} 
to della medesima rubrica sanzionava il complice del fuggitivo con la medesima pena riservata a questi ${ }^{232}$ : la questione, cionondimeno, non doveva apparire così scontata se il Bertazzoli si premurò, oltre che a riaffermare la necessità della sola inflizione dei due colpi di corda al Polletto e a negare recisamente quella di morte già toccata al compagno di prigionia in quanto omicida, di suffragare le proprie conclusioni anche citando l'ormai familiare stylus del Senato di Milano secondo l'interpretazione di Giulio Claro:

et certe negari non potest, quin teneretur ea poena duorum ictuum funis, qui ad poenam pro delicto iam commisso, homicidi mortis non punitur, ex forma huius statuti, sed tantum in casu fractionis cum fuga, quo casu statutum supra disposuit ipsum haberi pro confesso, et puniri posse ac si vere confessus fuisset, quod et iure communi conforme est [...]. Et quod quando quis carcerem frangat, sed tamen non aufugit, ut quia non fuit perfecte fractus aut aliter fuit impeditus, non habeatur pro confesso vel puniatur poena I.1.de effracto.et.expilat. [D. 47.18.1, I. de iis] declarat Albericus in l.in eos.num.2.ff.de custo.reo. [D. 48.3.13, I. in eos] [...], quae opinio etiam practicatur in senatu Mediolanensi ut refert lulius Clarus ${ }^{233}$ in practica criminale in.§ fin.q.21.vers.3.autem modo.in fin.. ${ }^{234}$

La relativa severità riservata dagli statuti di Mirandola al complice del fuggitivo, del resto, sembrò andare incontro allo stesso destino toccato anche alla punizione dell'evaso, ossia verso una sua progressiva incorporazione entro i vasti poteri discrezionali riconosciuti all'arbitrium iudicis (come, del resto, l'espresso rimando del Bertazzoli al senatore di Milano autorizza ad intendere): tanto Claro quanto Farinacci, ad esempio, riportano, nelle rispettive practicae, i casi di due mogli che, con le loro azioni, avevano sottratto abilmente i mariti alla spada della giustizia ma che non erano poi state punite con tutta la rigidità che ci si aspetterebbe dalle norme romanistiche delle quali si è qui discorso.

Nel caso di Allegra Piva ${ }^{235}$, infatti, il Senato di Milano dibatté lungamente intorno alla pena più opportuna con la quale sanzionare questa donna che era riuscita ad evitare al marito il patibolo, riparandosi, con decreto del 3 luglio del 1563 , dietro ad un sostanziale non liquet e limitandosi ad un generico ordine che nessuna molestia le dovesse toccare sino a nuove disposizioni; decisamente più

${ }^{232}$ Bartholomaeus Bertazzolius, 1602, fol. 77r: «et quod circa fractionem dictorum carcerum, aut circa fugam dictorum carceratorum, aut alicuius eorum praestiterit auxilium, consilium, vel favorem, puniatur et condemnetur illam et poena, qua punietur et condemnabitur ipse frangens, vel fugiens».

233 Il luogo è il medesimo citato supra in lulius Clarus, 1574, foll. 77r-83r.

${ }^{234}$ Bartholomaeus Bertazzolius, 1602, fol. 77r.

235 Iulius Clarus, 1574, fol. 92r: «non tamen omittam, quod cum quaedam Alegra Piva maritum capitaliter damnatum exemisset a manibus satellitum, fuit diu disputatam in Senatu, an esset punienda, et tandem non fuit diffinitive absoluta neque condemnata, sed dictum eam non esse molestandam, donec aliud per Senatum ordinatum fuisset.3.lul.1563». 
scoperte le simpatie del Farinacci per la dedizione dimostrata da una donna che, sul finire del XVI secolo, si era introdotta, assieme alle altre mogli dei carcerati, «in curia de Sabellis» ${ }^{236}$ e, recando con sé una veste muliebre celata in un involto, aveva travestito, approfittando dell'occasione fornitale da una visita coniugale, il marito, il quale era poi riuscito a confondersi con le altre donne e con sua moglie, evadendo dal carcere attraverso i cancelli, il tutto "cum maxima et ridiculosa omnium admiratione, post quam res fuit patefacta ${ }^{237}$. Al termine di questa rievocazione dal sapore un po' donchisciottesco, Farinacci propende decisamente per I'inflizione di una pena straordinaria, specie alla luce dei commendevoli motivi che avevano mosso la donna a soccorrere il suo sposo ${ }^{238}$.

Anche alla prassi dell'Inquisizione romana, del resto, non erano ignote le problematiche inevitabilmente conseguenti all'evasione dei propri prigionieri: in un caso riportato, con una certa dovizia di dettagli, nella praxis di fra' Umberto Locati O.P. ${ }^{239}$ (1503-1587), ad esempio, si apprende ${ }^{240}$ di un chierico che, già sospettato di pratiche ereticali e per tale ragione trattenuto dall'inquisitore ${ }^{241}$, teneva presso di sé un breviario incriminante, avendovi sopra raffigurato immagini oltraggiose ritraenti Gesù Cristo e la Madre di Dio ${ }^{242}$.

De supradictis interrogatus ipse clericus negavit de his aliquid scivisse. Hic post factum examen, dum per custodem de carcere reduceretur, fugam fecit, ac per altam dormitorii fratrum fenestram super tectum quoddam ascendit, indeque in viam publicam praecipitem se dedit. Fracto igitur latere iterum in carcerem portatus, cum iam per dies septuaginta manserit, nec adhuc sanitati restitutus sit,

\footnotetext{
${ }^{236}$ Prosperus Farinacius, 1589, fol. 305r.

${ }^{237}$ Prosperus Farinacius, 1589, fol. 305r.

${ }^{238}$ Prosperus Farinacius, 1589, fol. 333v: «videtur hanc mulierem propter intensum amorem quo pro sequitur virum suum, et propter obedientiam quam eidem viro praestare tenetur, forse excusandam a poena ordinaria: sed ab extraordinaria et in totum vix credo in practica obtineri posse».

${ }^{239}$ Un'analisi della vita e delle opere, e specie di quelle giuridiche, del vescovo domenicano in Donati, 2021, pp. 439-457.

${ }^{240}$ L'appendice di casus proposti dal Locati in appendice alla propria opera di procedura penale è unica - perlomeno a quel che consta a chi scrive - nel panorama della letteratura destinata all'Inquisizione romana: quello del quale qui si discute, in Umbertus Locatus, 1583, fol. 456, è da ricomprendere i quindici «per diversos iuris utriusque doctores ad Inquisitoris instantiam, Placentiae discussi» Umbertus Locatus, 1583, fol. 450.

${ }^{241}$ Tutti i casi tramandati nel casebook della Praxis sono stati trattati avanti il Locati medesimo (Donati, 2021, p. 446).

242 Umbertus Locatus, 1583, fol. 456: «Penes sacerdotem de haeresi suspectum, et in fortiis domini Inquisitoris, ut de fide responderet detentum, breviarium repertum fuit, in cuius primo folio scriptum erat, diabolus hic, ac in dicti breviarii folio ultimo depicta erat imago Beatissimae Dei Genitricis Domini nostri lesu Christi figuram in gremio continens, quorum utraque imago effosis oculis etiam in variis locis sfrisata erat».
} 
quaeritur quid de illo sit agendum?243

II rovinoso tentativo di fuga del chierico attraverso il tetto del monastero presso il quale era detenuto e la conseguente, infausta caduta obbligarono il Locati a cercare il consulto del pretore di Piacenza, "Bernardus Bregontius»" 244 e a domandargli, in particolare, se, specie alla luce della grave ferita riportata, l'imputato potesse essere sottoposto, «ad purganda indicia ac etiam pro habenda veritate ${ }^{245}$, ad una sessione di tortura.

La risposta del pretore e del suo consultorio riveste un particolare interesse ai fini del presente contributo non tanto per la ricomprensione entro la categoria di crimen lesae maiestatis divina ${ }^{246}$ delle condotte attribuite allo sfortunato sacerdote quanto perché il tentativo d'evasione viene citato tra le ragioni che avrebbero autorizzato il Locati a procedere alla tortura giudiziale, pur previamente raccolta l'opinione favorevole di un medico che attestasse l'assenza di maggiori pericoli o infermità per l'imputato ${ }^{247}$ : da questo punto di vista, la mancanza di qualsiasi menzione di più gravi e definitivi provvedimenti, desumibili dalla sola fuga, in ordine alla colpevolezza del reo - dei quali si è sinora discorso - può contribuire a confermare l'impressione che, alla metà del XVI secolo, la materia dell'evasione dal carcere avesse cominciato a gravitare sempre più entro l'orbita dell'arbitrium iudicis - anche questo, peraltro, puntualmente citato nel consilium del pretore -, a tutto discapito delle pene capitali di ascendenza giustinianea.

Venendo ora ad alcuni ${ }^{248}$ pronunciamenti di corti sovrane in tema d'evasione, la prima vicenda a venire in rilievo proviene dai ruoli della Rota di Lucca: tramandato da Girolamo Magoni ${ }^{249}$ (1530-1596) nella sua silloge di decisiones, il caso

${ }^{243}$ Umbertus Locatus, 1583, fol. 456.

244 Umbertus Locatus, 1583, fol. 456.

245 Umbertus Locatus, 1583, fol. 456.

${ }^{246}$ Per la cui definizione si rimanda a Sbriccoli, 1974.

${ }^{247}$ Umbertus Locatus, 1583, fol. 456: «vidimus ea quae contra sacerdotem suspectum de haeresis nobis significastis, ea omnia in consilio nostro proposuimus, et ita nos omnes re inter nos bene pensata, censuimus medicos esse consulendos, qui si retulerint nullum subesse periculum maioris, seu deterioris infirmitatis, ubi iste suspectus quaestioni et tormentis admoveatur, illum utique torqueri debere, cum sit admodum suspectus de haeresi, stantibus verbis illis in horario eius scriptis, videlicet, diabolus hic. Item stante conscissione imaginis divae Virginis, et Domini Nostri lesu Christi, et fuga eiusdem praesbyteri. Nam conscindere, et spurcare imagines sanctorum, nedum divae Virginis, et Domini Nostri lesu Christi, crimen est capitale, quod plurimum ad haeresim tendit, quia laedit divinam maiestatem. Et haec pauca sufficiant, omnia remittentes prudentissimo arbitrio r.p.v. cui me plurimum commendo».

${ }^{248}$ Le decisiones che qui si proporranno hanno, lo si rimarca, carattere meramente esemplificativo.

${ }^{249}$ Sul giureconsulto orvietano, auditore sia a Lucca che a Firenze, oltre che podestà sempre a Lucca, può vedersi Nappo, Noto, 2002. 
riguardava una certa "Lucretia de Vitriano ${ }^{250}$, già condannata ad una non meglio circostanziata "poenam capitis» ${ }^{251}$, la quale si trovava ad essere detenuta (peraltro in stato di gravidanza) presso il palazzo del podestà di Castiglione di Garfagnana, sistemazione ritenuta più conveniente per le sue condizioni fisiche e lontana da indebite attenzioni maschili ${ }^{252}$. Nonostante queste precauzioni, Lucrezia riuscì a fuggire di prigionia giovandosi dell'aiuto esterno di "Laurentio et Baldo » ${ }^{253}$ : nottetempo, infatti, e in una notte tempestosa - descrive dettagliatamente il Magoni -, mentre Baldo era intento a montare la guardia al castello, Lorenzo riuscì, da questi coadiuvato, a raggiungere, servendosi di funi e scale, la cella di Lucrezia, liberandola così dal palazzo del podestà 254 .

A seguito della fuga, si presentò il problema della pena da irrogare a Baldo, la guardia del castello complice di Lorenzo ${ }^{255}$ : prima facie, infatti, esordisce il Magoni giovandosi anche dell'auctoritas di alcuni dei giuristi già qui esaminati, sembrerebbe che al complice spetti la medesima sanzione irrogata all'evaso ${ }^{256}$; alcuni dubbi, cionondimeno, sorsero a seguito di un accurato esame delle disposizioni statutarie in materia, secondo le quali al complice sarebbe toccata in sorte la medesima pena del fuggitivo solo nel caso l'evento evasivo fosse occorso a seguito di fuga da un carcere pubblico ${ }^{257}$. Come si ricorderà, infatti, Lucrezia, specialmente a causa della sua gravidanza, non era detenuta in carcere ma presso il palazzo podestarile: nel ragionamento che porterà alla condanna di Baldo - la cui condotta venne peraltro giudicata particolarmente riprovevole in ragione del suo servizio militare, considerevolmente aggravata, cioè, dalla circostanza che

\footnotetext{
250 Hieronymus Magonius, 1605, fol. 239.

${ }^{251}$ Hieronymus Magonius, 1605, fol. 239.

252 Hieronymus Magonius, 1605, fol. 239: «devenerat in fortiam Curiae domina Lucretia de Vitriano in poenam capitis condemnata, quae cum esset mulier, et praegnans, et ex causa criminali damnata [...] detinebatur in palatio domini potestatis Castri Castilionis, quod loco tuti carceris ei assignatum fuerat sic exigente loci qualitate propter penuriam carcerum et sexum mulieris honestatem, seorsum a masculis detinentur».

253 Hieronymus Magonius, 1605, fol. 239.

${ }^{254}$ Hieronymus Magonius, 1605, fol. 239: «interim conspirantibus Laurentio et Baldo de ea abducenda, et e carceribus eximenda, Baldus dum esset in excubiis dicti Castri, nocte intempesta scalis, ac funibus per trascensionem murorum Laurentium intromisit, statimque cum dictis instrumentis ad palatium domini Potestatis properantes datis signis illam per fenestras eduxerunt, et per descensionem murorum evadere fecerunt».

${ }^{255}$ Nessuna ulteriore menzione si fa, nel consilium de quo, circa il destino toccato a Lucrezia e Lorenzo.

${ }^{256}$ Hieronymus Magonius, 1605, fol. 239: «et inspecta iuris communis dispositione videbatur concludendum paritate poenae eum teneri, ac si in omnem casum pro ea fideiussisset, ut per [...] Bossium [...] et Menochium».

${ }^{257}$ Hieronymus Magonius, 1605, fol. 239: «sed dubium faciebat statutum, cuius verba sunt haec: "quod faciens evadere aliquem e carceribus publicis aliter, quam frangendo carceres, puniatur eadem poena qua puniendus erat is, qui aufugit" $»$.
} 
egli aveva abusato del suo ufficio per favorire la commissione di un crimine ${ }^{258}$ alla stessa pena capitale già irrogata (anche se non eseguita) contro Lucrezia ${ }^{259}$, Magoni ordinò i passaggi concettuali attraverso i quali, a partire dall'evidente differenza di destinazione che corre tra l'aedificium carcerario e quello podestarile, la corte finì per punire la sentinella, andando ad ampliare la portata semantica del dettato statutario.

Quod statutum, et si prima fronte idem cum iure communi disponere iudicatur, tamen ex quo requirit ad huiusmodi poenam incurrendam carceres esse publicos, non videtur in casu isto identitas poenae infligenda, quia Palatium in carcerem datum non dicitur proprie carcer publicus, sed large, et interpretative, et cum statuta poenalia sint stricte intelligenda, et in casu vero non ficto, merito alia et benignior poena arbitranda est [...].

Contraria tamen opinio uti verior magis placuit, videlicet cameram, et palatium in carcerem iudicibus assignatum, publicum carcerem dici debere [...]. Carceres enim publicus dicitur non solum locus ille, qui perpetuis custodibus custoditur, et foris clavibus aperitur, sed omnis alius locus in carcerem assignatus, quia publicus sit sola iudicis destinatione et mandato ${ }^{260}$.

Un vivido spaccato delle vicende che potevano interessare la vita di un carcere di provincia è poi offerto nel Codex casuum selectorum ${ }^{261}$ di Giovanni Battista del Toro, giureconsulto napoletano, nel quale è tramandato il caso di un detenuto già condannato che, avvalendosi di una "falsa clave ${ }^{262}$, era riuscito ad aprire le porte del castello di Teano nel quale era rinchiuso: alla fuga, però, prese parte anche un detenuto per il quale il procedimento non era ancora concluso (il del Toro lo qualifica «inquisitus» ${ }^{263}$ ) e che, soprattutto, si era trovato ad approfittare, senza avere in alcun modo partecipato alla preparazione del piano evasivo, dei cancelli già aperti dagli altri ${ }^{264}$. Avendo il del Toro preso possesso del giudicato di Teano il 24 marzo 1614 ed essendo il fatto occorso alcuni giorni dopo ${ }^{265}$, toccò proprio all'autore affrontare la spinosa questione della punizione di quest'ultimo

${ }^{258}$ Hieronymus Magonius, 1605, fol. 239: «Baldum [...] cuius delictum eo gravius reddebatur, quia in officio, et quidem militari deliquerat».

${ }^{259}$ Hieronymus Magonius, 1605, fol. 239: «et per ista dicebamus eadem poena, qua domina Lucretia punienda fuisset, Baldum fore [...] capitali poena puniendum».

${ }^{260}$ Hieronymus Magonius, 1605, fol. 239.

261 Iohannes Baptista de Thoro, 1655.

262 Iohannes Baptista de Thoro, 1655, fol. 121.

263 Iohannes Baptista de Thoro, 1655, fol. 121.

264 Iohannes Baptista de Thoro, 1655, fol. 121: «accidit per quendam carceratum, et condemnatum, cum falsa clave ostium Castri apertum, et multi carcerati ex quo aufugierunt, et inter eos unus inquisitus viso hostio aperto similiter aufugit».

265 Iohannes Baptista de Thoro, 1655, fol. 121: «antequam possessionem officii iudicatus in civitate Theanesi coepisse [...]; suscepta possessione officii praedicti die 24 Martii 1614». 
fuggitivo e, più in particolare, se questi fosse da considerare confessus del reato per il quale era indagato al momento dell'evasione ${ }^{266}$.

Sebbene, infatti, potesse sembrare, di primo acchito, che qualsiasi fuga importasse per l'evaso la qualifica di fictus confessus, una disamina più attenta delle fonti dottrinarie condusse il del Toro a distinguere tra fuga con o senza cospirazione previa e con o senza compromissione dell'integrità dell'edificio carcerario ${ }^{267}$ : così, «hodie $»^{268}$, colui che evada trovando le porte del carcere aperte non è certo considerato quale reo confesso del crimine per il quale era stato originariamente carcerato ${ }^{269}$; anzi, prosegue il del Toro con un obiter dictum assai interessante per il presente contributo, "veritas est», sia che la fuga sia seguita, sia che si sia arrestata allo stadio di mero tentativo, "effractores carcerum puniuntur poena arbitraria» ${ }^{270}$.

Anche traversato il Mediterraneo, del resto, le questioni che si facevano strada sino alle scrivanie dei giudici presentavano simili problematiche: di un'evasione facente mostra di tutti i crismi della più grave sorta tratta, ad esempio, il giudice catalano Lluís de Peguera ${ }^{271}$ (1540-1610). II 7 novembre 1581, infatti, il Sacro Regio Consiglio di Catalogna accolse le conclusioni formulate dal procuratore regio contro "Hieronimum Salas» ${ }^{272}$, condannato per aver cospirato coi propri compagni di prigionia, rotto i vincoli che lo tenevano incatenato ed infine effranto le mura del carcere. L'elemento qui più interessante è però la natura della pena irrogata a Girolamo: dopo aver dispiegato, infatti, densi argomenti tesi a dimostrare come le mura delle carceri siano «loca sacra»" ${ }^{273}$, de Peguera afferma come qualsiasi violazione di queste comporti, per il violatore, una pena di natura capitale.

Sacra loca ea sunt, quae publicae dedicata sunt, sive in agro, sive in civitate sint. Et sic muri, et fores carcerum qui publicis usibus destinantur [...] sancti sunt; sicut muri civitatis. Sed rumpens vel violans sanctum capunite punitur [...]. Ergo rum-

\footnotetext{
${ }^{266}$ Iohannes Baptista de Thoro, 1655, fol. 121: «fuit dubitatum si poterat ex hac fuga puniri; nam et si regula sit, ut aufugiens de carcere habetur pro confesso».

${ }^{267}$ Iohannes Baptista de Thoro, 1655, fol. 121: «sed hoca sane doctores intelligunt quando praevia conspiratione actum fuerit, et tunc pro confesso habetur, alias non [...], nec haberetur pro confesso et convicto [...]. Bene verum est, quod exigitur fractio carceris: $[\ldots]$ cessante fractione, non habetur pro confesso, [...] nec punitur poena effractionis carceris».

268 Iohannes Baptista de Thoro, 1655, fol. 121.

${ }^{269}$ Iohannes Baptista de Thoro, 1655, fol. 121: «si aperto hodie quisquam carceratus aufugerit, non habetur tunc pro confesso, [...] sicque fugiens e carceribus, non habetur pro confesso, quando carcer fuisset fractus a tertio, nec consilio, et suasione nunc fugientis [...] et successive non debet capitali poena puniri».

270 Iohannes Baptista de Thoro, 1655, fol. 121.

${ }^{271}$ Per il quale si rimanda a de Montagut, 2001-2002.

272 Ludovicus a Peguera, 1608, fol. $2 r$.

273 Ludovicus a Peguera, 1608, fol. $1 v$.
} 
pens vel violans carceres, poena iam dicta plectendus est ${ }^{274}$.

Cionondimeno, aggiunge subito il giurista catalano,

poena autem capitis, de qua dictae leges in nostro casu loquamur, non eam intelligamus, quae mortem naturalem infert, sed aliam mitiorem ${ }^{275}$.

Alla luce di tali considerazioni, la condanna perpetua al remo ${ }^{276}$ infine irrogata all'evaso è certo inquadrabile in un panorama più perspicuo ${ }^{277}$ : qualora, infatti, si mantenga - come nel caso discusso avanti il Sacro Regio Consiglio di Catalogna che la più grave evenienza d'evasione sia da punire con pena capitale - ma non con la morte -, la dura condanna alle regie galere risulta pienamente comprensibile, essendo anche quest'ultima ricompresa tra le pene che privano della libertà personale il condannato 278 .

\section{Conclusioni}

In anni successivi (ma non poi così lontani) a quelli nei quali Grotius evase dal castello di Loevestein, un altro olandese, il cattedratico Anton Mattheus II ${ }^{279}$ (16011654), pubblicava il suo fortunato commentario ${ }^{280}$ ai libri $47^{\circ}$ e $48^{\circ}$ delle Pandette. Allorché si trovò a ragionare sopra l'argomento "de carceris effractione» ${ }^{281}$, così concluse l'illustre criminalista:

Effractionem carceris crimen extraordinarium esse I.1.D.de effract.et.expil. [D. 47.18.1, I. de iis] arguit: sed quae poena criminis, admodum apud interpretes controversum est. Enata autem controversia ex verbis iurisconsultorum, qui de poena capitis cum sint locuti disputarunt interpretes, ultimumne supplicium sit intelligendum, an poena aliqua mitior. [...]

\footnotetext{
${ }^{274}$ Ludovicus a Peguera, 1608, fol. $2 r$.

275 Ludovicus a Peguera, 1608, fol. $2 r$.

${ }^{276}$ Sulla quale si rimanda ad Angiolini, 2006.

277 Ludovicus a Peguera, 1608, fol. $2 r$ : «et secundum ultimam opinionem fuit in regio criminali consilio Cathaloniae conclusum die 7 mensis novembris 1581 in facto fisci procuratoris regiae curiae contra Hieronimum Salas, delatum et inculpatum, quod cum receptus esset, in carcerem conspiraverit, et ruptis vinculis, et effracto carcere, cum aliis ab eisdem evaserit, qui etiam erat detentus pro aliis delictis, sine dubio fuisset reus mortis. Et tamen fuit condemnatus pro dicta conspiratione, fuga, et effractura, attentis etiam aliis delictis de quibus tantum erat infamatus ad servitium regiarum triremium imperpetuum».

${ }^{278}$ Per la sussunzione della condanna al remo tra le pene capitali si veda, oltre a quanto esposto supra, Angiolini, 2006.

${ }^{279}$ Per la vita e la produzione scientifica del quale si rimanda a Martyn, 2016 e specialmente a Pollorsi, 2015.

${ }^{280}$ Antonius Matthaeus, 1672.

${ }^{281}$ Antonius Matthaeus, 1672, foll. 257-260.
} 
Porro, quamvis in adductis iurisconsultorum responsis per poenam capitis ultimum supplicium intelligendum contenderimus, non tamen id ita accipi voluimus, tanquam iudex semper effractoribus poenam mortis irrogare debeat, ac nunquam mitiorem infligere possit. Quippe crimen hoc extraordinarium est: necesse est ergo relinqui aliquid arbitrio iudicis, ut et personarum, et criminis admissi, et armorum quibus effractor usus est, rationem habeat ${ }^{282}$.

Le parole testé riportate del Mattheus suonano come una ben pizzicata ultima nota offerta dallo spartito intellettuale sinora riproposto: oltre a ribadire, infatti, come la questione della punizione degli evasi dalle pubbliche carceri fosse tutt'altro che incontroversa in seno alla dottrina, il giurista olandese giunse, specialmente attraverso l'utilizzo della categoria di crimen extraordinarium ${ }^{283}$, alle medesime conclusioni cui, nel corso della prima età moderna, sembrava essere approdata anche la gran parte dei criminalisti, tracciando una rotta che, a partire da un'interpretazione aderente alla lettera della norma giustinianea, aveva condotto verso una progressiva mitigazione delle sanzioni da riservare a chi fuggisse di prigionia.

Sono perlomeno due, in proposito, i punti che si desidera qui far maggiormente risaltare: anzitutto, il florilegio di opinioni che si è voluto sottoporre all'attenzione del lettore sembra costituire materiale sufficiente dal quale poter prendere le mosse per un inquadramento sempre più dettagliato del rapporto intercorrente tra giuristi della tradizione giuridica europea e materia carceraria. Ancora una volta ${ }^{284}$, infatti, le fonti considerate più tradizionalmente di cognizione per la ricostruzione del pensiero scientifico dello ius commune appaiono più che in grado di restituire all'attenzione dell'interprete un quadro variegato e quantomai complesso delle concrete vicissitudini che, quotidianamente, la realtà presentava all'attenzione degli operatori del diritto, impegnati in prima linea a confrontarsi con essa. Lungi dal costituire un'inaccessibile casta di intellettuali scollegati dalla realtà, il tema dell'evasione carceraria ha offerto semmai un'ulteriore occasione per dimostrare quanto i giuristi medievali e della prima età moderna potessero contribuire ad imbrigliare entro schemi se non umani certo meno caotici una realtà in continua e perpetua evoluzione.

In secondo luogo, non può non rimarcarsi, ancora una volta, come l'interpretazione dottrinale delle norme giustinianee con le quali si sono aperte le presenti riflessioni si sia progressivamente mossa a caldeggiare più miti e misericordiose conclusioni rispetto alla durezza che la littera legis autorizzava a concepire: se si confrontano, ad esempio, le spigolose riflessioni dell'anonimo del De carceribus con quelle quasi compartecipi ed ammirate del Farinacci a proposito della moglie che riuscì a liberare il marito dalle prigioni della Corte Savella con lo stratagemma

\footnotetext{
282 Antonius Matthaeus, 1672, foll. 257, 259.

${ }^{283}$ Per il rapporto tra arbitrium iudicis e crimen extraordinarium il rimando è a Meccarelli, 1998.

${ }^{284}$ Donati, 2020a, pp. 176-177.
} 
picaresco del travestimento muliebre, si noterà - ma in effetti, come visto, già in pieno Trecento le posizioni di grandi nomi del diritto comune non propendevano certo accoratamente per l'inflizione dell'ultimo supplizio - come l'intervento dei giuristi, nel corso dei secoli e nelle diverse modalità concesse ora al giurista professore, ora al giurista consulente, ora al giurista giudice, si rivelò quale forza vieppiù moderatrice, destinata a far emergere, dall'inarrestabile vortice della realtà, questa o quella circostanza ${ }^{285}$ che, se certo non impedì al diritto penale dell'epoca di riuscire inaccettabilmente iniquo a sensibilità contemporanee, contribuì, perlomeno, a non aggravare una situazione già evidentemente difficoltosa come quella dei detenuti (si pensi alle parole, tremende, di Egidio Bossi, costretto ad intervenire perché quegli evasi obbligati dalle circostanze della loro cattività a fuggire per non morire di freddo e di stenti non fossero ulteriormente brutalizzati).

In proposito, il trattamento riservato alla moglie di Grotius - alla quale, come detto, fu concesso di ricongiungersi al marito senza subire molestia di sorta da parte delle autorità olandesi - può certo contribuire a rendere ancor più lieta questa nota conclusiva. In effetti, proprio a quest'ultimo aspetto - la punizione del complice - si riferiscono le parole finali della riflessione del Mattheus in tema di effrazione carceraria:

non solum vero puniuntur extra ordinem ipsi qui eruperunt, sed etiam qui opem eis tulerunt [...]. Nostra vero aetate etiam prorsus impune fuit uxori viri doctissimi, quae maritum maiestatis reum cistae inclusum callidissimo commento e carcere eduxerat ${ }^{286}$.

Difficile non scorgere in quest'uomo dottissimo e nella di lui moglie che lo fece evadere in una cassa, con uno stratagemma astutissimo, proprio quell'Hugo e quella Maria colle vicende dei quali si son principiate le presenti riflessioni.

\section{Bibliografia}

Aegidius Bossius, 1580: Practica et tractatus varii, seu quaestiones Aegidii Bossii, patricii mediolanensis, iurisconsulti longe clarissimi, cesareique senatoris, Basileae, Per Sebastianum Henricpetri

Albericus de Rosate, 1585: Alberici de Rosate bergomensis, iurisconsulti clarissimi, ac summi practici, in Secundam ff. Novi partem Commentarii, Venetiis, Societas ad signum aquilae

Alessi G., 2013: «Economie del penale» nell’età moderna, in A. Calore, A. Sciumè

${ }^{285}$ E quindi, come i casi tramandati dal Magoni e dal de Peguera stanno a dimostrare, non solo a favore ma anche contra reum.

${ }^{286}$ Antonius Matthaeus, 1672, fol. 260. 
(eds.), La funzione della pena in prospettiva storica e attuale, Milano, Giuffrè, pp. 125-145

Alexander Tartagnus, 1590a: Consiliorum seu responsorum Alexandri Tartagni [...] Liber Secundus, Venetiis, Apud Felicem Valgrisium

Alexander Tartagnus, 1590b: Consiliorum seu responsorum Alexandri Tartagni [...] Liber Tertius, Venetiis, Apud Felicem Valgrisium

Angelus Aretinus, 1599: Tractatus de maleficiis, Coloniae Agrippinae, Apud viduam Henrici Falckenburg

Angiolini F., 2006: La pena della galera nella Toscana moderna (1542-1750), in L. Antonielli (ed.), Carceri, carcerieri e carcerati. Dall'antico regime all'Ottocento, Soveria Mannelli, Rubbettino, pp. 79-115

Antonielli L. (ed.), 2006: Carceri, carcerieri, carcerati. Dall'antico regime all'Ottocento, Soveria Mannelli, Rubbettino

Antonius Mattheaeus, 1672: De criminibus ad libros XLVII et XLVIII Digesti Commentarius, Vesaliae, Typis Andreae ab Hoogenhuysen

Archidiaconus, 1577: Guidonis a Bayiso archidiaconi bononiensi iuris utriusque peritissimi in Sextum decretalium Commentaria [...], Venetiis, Apud luntas

Ascari T., 1967: Bertazzoli, Bartolomeo, in Dizionario Biografico degli Italiani, 9, Roma, Istituto della Enciclopedia Italiana, ad vocem

Ascheri M., 1989: Tribunali, giuristi e istituzioni dal medioevo all'età moderna, Bologna, II Mulino

Ascheri M., 2012: I grandi tribunali, in P. Cappellini, M. Fioravanti, B. Sordi (eds.), Enciclopedia italiana di scienze, lettere ed arti. II contributo italiano alla storia del pensiero. Ottava appendice. Diritto, Roma, Istituto dell'Enciclopedia Italiana, pp. 121-128

Baldus de Ubaldis, 1575: Baldi Ubaldi perusini iurisconsulti omnium concessu doctissimi pariter et acutissimi, consiliorum siver responsorum, volument tertium, Venetiis, Apud Hieronymum Polum

Baldus de Ubaldis, 1615: Baldi Ubaldi perusini [...] in VII, VIII, IX, X e XI Codicis libros Commentaria, Venetiis, Apud haeredes Georgii Varisci

Bartholomaeus Bertazzolius, 1602: Decisivarum consultationum sive responsorum iuris in criminalibus et poenalibus controversiis [...], Francofurti ad Moenum, E Nobilis Francofurti Paltheniana

Bartocci A., 2013: Giovanni d'Andrea, in I. Birocchi, E. Cortese, A. Mattone, M. N. Miletti (eds.), Dizionario Biografico dei Giuristi Italiani (XII-XX secolo), Bologna, Il Mulino, pp. 1008-1012

Bartolus a Saxoferrato, 1590: Bartoli a Saxoferrato, omnium iuris interpretum antesignani Commentaria [...] in secundam Digesti Novi partem, Venetiis, Apud luntas 
Bellomo M., 1974: Aspetti dell'insegnamento giuridico delle università medievali. I. Le quaestiones disputatae, Reggio Calabria, Parallelo 38

Bellomo M., 2000: I fatti e il diritto tra le certezze e i dubbi dei giuristi medievali (secoli XIII-XIV), Roma, II Cigno Galileo Galilei

Berman H. J., 1998: Diritto e rivoluzione. Le origini della tradizione giuridica occidentale, Bologna, II Mulino

Birocchi I., Miletti M. N., 2013: Follerio, Pietro, in I. Birocchi, E. Cortese, A. Mattone, M. N. Miletti (eds.), Dizionario Biografico dei Giuristi Italiani (XII-XX secolo), Bologna, II Mulino, p. 885

Bretschneider F., Claustre J., Heullant-Donat I., Lusset E. (eds.), 2015: Enfermements II. Règles et déréglements en milieu clos (IVe-XIXe siècle), Paris, Publications de la Sorbonne

Bretschneider F., Claustre J., Heullant-Donat I., Lusset E. (eds.), 2017: Enfermements III. Le genre enfermé. Hommes et femmes en milieux clos (XIIIeXXe siècle), Paris, Publications de la Sorbonne

Carrai S., Maffei, P., 2018: Sinibuldi (Sigibuldi, Sighibuldi, Sigisbuldi), Cino (Cino da Pistoia), in Dizionario Biografico degli Italiani, 92, Roma, Istituto dell'Enciclopedia Italiana, pp. 791-796

Cavina M., 2013a: La redenzione sul patibolo. Funzioni della pena bassomedievale, in A. Calore, A. Sciumè (eds.), La funzione della pena in prospettiva storica e attuale, Milano, Giuffrè, pp. 93-124

Cavina M., 2013b: Marsili, Ippolito, in I. Birocchi, E. Cortese, A. Mattone, M. N. Miletti (eds.), Dizionario Biografico dei Giuristi Italiani (XII-XX secolo), Bologna, II Mulino, pp. 1286-1287

Chiodi G., 2015: Cristianesimo medievale e diritto, in M. Benedetti (ed.), Storia del cristianesimo. II. L'età medievale (secoli VIII-XV), Roma, Carocci, pp. 163-185

Claustre J., Heullant-Donat I., Lusset E. (eds.), 2011: Enfermements. Le cloître et la prison (Vle-XVIIle siècle), Paris, Publications de la Sorbonne

Codex, 1558: Codicis domini lustiniani sacratissimi principis, ex repetita praelection libri novem priores, ad vetustissimorum exemplarium, et ad ipsius eriam Noricae editionis (quam Haloandro debemus) fidem recogniti et emendati, Lugdunum, Apud Hugonem a Porta et Antonium Vincentium

Colli V., 1991: /l Cod. 351 della Biblioteca Capitolare "Feliniana" di Lucca: editori quattrocenteschi e Libri consiliorum di Baldo degli Ubaldi (1327-1400), in M. Ascheri (ed.), Scritti di storia del diritto offerti dagli allievi a Domenico Maffei, Padova, Editrice Antenore

Colli V., 2005: Le opere di Baldo dal codice d'autore all'edizione a stampa, in C. Frova, M. G. Nico Ottaviani, S. Zucchini (eds.), VI Centenario della morte di Baldo degli Ubaldi 1400-2000, Perugia, Università degli Studi di Perugia, pp. 25-85 
Condorelli O., 2013: Niccolò Tedeschi, in I. Birocchi, E. Cortese, A. Mattone, M. N. Miletti (eds.), Dizionario Biografico dei Giuristi Italiani (XII-XX secolo), Bologna, II Mulino, pp. 1426-1429

Condorelli O., 2014: Un contributo bolognese alla dottrina del processo romanocanonico: il Tractatus de accusationibus et inquisitionibus di Bonincontro di Giovanni d'Andrea (+1350), in Y. Mausen, M. Schmoeckel, O. Condorelli, P. Roumy (eds.), Der Einfluss der Kanonistik auf die Europäische Rechtskultur. Bd. 4. Prozessrecht, Köln-Weimar-Wien, Böhlau, pp. 65-90

Condorelli O., 2015: Pietro d'Ancarano, in Dizionario Biografico degli Italiani, 83, Roma, Istituto della Enciclopedia Italiana, pp. 444-448

Condorelli O., 2019: Tedeschi, Niccolò, in Dizionario Biografico degli Italiani, 95, Roma, Istituto della Enciclopedia Italiana, pp. 266-271

Constitutiones Mediolani, 1616: Constitutiones provinciae mediolanensis, cum decretis ordinibus et declarationibus Senatus, Mediolani, Cura et sumptu lohannis Baptistae Bidellij

Cortese E., 1995: II diritto nella storia medievale. II. II Basso Medioevo, Roma, II Cigno Galileo Galilei

Cortese E., 2013: Baldo degli Ubaldi, in I. Birocchi, E. Cortese, A. Mattone, M. N. Miletti (eds.), Dizionario Biografico dei Giuristi Italiani (XII-XX secolo), Bologna, II Mulino, pp. 149-152

Cortese E., Pennington K., 2013: Pietro d'Ancarano, in I. Birocchi, E. Cortese, A. Mattone, M. N. Miletti (eds.), Dizionario Biografico dei Giuristi Italiani (XII-XX secolo), Bologna, II Mulino, pp. 1578-1580

Cynus Pistoriensis, 1578: In Codicem et aliquot titulos primi Pandectorum tomi, id est, Digesti veteris, doctissima Commentaria [...], Francoforti ad Moenum, Impensis Sigismundi Feyerabendt

De carceribus, 1584: Tractatus multum conductibilis de carceribus, in Tractatus universi iuris, duce, et auspice, Gregorio XIII pontifice maximo in unum congesti ..., Venetiae, Societas aquilae se renovantis, XI.I, foll. 200v-201v

de Montagut T., 2001-2002: Pràctiques parlamentàries a Catalunya en el segle XVI i la sva fomulació escrita per Lluís de Peguera, in "lus fugit", 10-11, pp. 633656

Dezza E., 1989: Accusa e inquisizione. Dal diritto comune ai codici moderni. I, Milano, Giuffrè

Dezza E., 2002: «Pour pourvoir au bien de nostre justice». Legislazioni statali, processo penale e modulo inquisitorio nell'Europa del XVI secolo, in "Acta Histriae", 10, pp. 7-38

Dezza E., 2013: Lezioni di storia del processo penale, Pavia, Pavia University Press

Dezza E., 2016: La giustizia penale di un tribunale ecclesiastico di antico regime: 
il vicario criminale della curia ambrosiana (secc. XVI-XVII), in A. Cascetta, D. Zardin (eds.), Giustizia e ingiustizia a Milano fra Cinque e Seicento, Milano, Biblioteca Ambrosiana, pp. 247-294

Dezza E., 2017: II Granduca, i filosofi e il codice degli Irochesi. II principio contumax pro confesso habetur e la riforma leopoldina, in "Italian Review of Legal History", 3, pp. 1-79

Digestum Novum, 1558: Digestum novum Pandectarum iuris civilis tomus tertius, Lugdunum, Apud Hugonem a Porta et Antonium Vincentium

di Renzo Villata M. G., 1996: Egidio Bossi, un grande criminalista milanese quasi dimenticato, in lus Mediolani. Studi di storia del diritto mediolanese offerti dagli allievi a Giulio Vismara, Milano, Giuffrè, pp. 365-616

di Renzo Villata M. G., 2008: Tra consilia, decisiones e tractatus ... Le vie della conoscenza giuridica nell'età moderna, in "Rivista di Storia del Diritto Italiano", 81, pp. $15-76$

di Renzo Villata, 2013 M. G.: Bossi, Egidio, in I. Birocchi, E. Cortese, A. Mattone, M. N. Miletti (eds.), Dizionario Biografico dei Giuristi Italiani (XII-XX secolo), Bologna, II Mulino, pp. 316-319

Dominicus a Sancto Geminiano, 1578: In Sextum decretalium volumen Commentaria, Venetiis, Apud luntas

Donati G. A., 2020a: «Non modo omnibus notissimum est»: prime note intorno alla pena detentiva nel diritto comune (secc. XIV-XVI), in "Rivista di Storia del Diritto Italiano", 93, pp. 125-177

Donati G. A., 2020b: Al crocicchio dei saperi. Prime note sul rapporto tra diritto e teologia nelle practicae dei domenicani Umberto Locati (1503-†1587) e Pietro Maria Passerini (1597-+1677), in E. Ivetic (ed.), Attraverso la storia. Nuove ricerche sull'età moderna, Napoli, Editoriale Scientifica, pp. 353-377

Donati G. A., 2021: Iuste iudex ultionis. Inquisizione romana, ordo Praedicatorum e cultura giuridica in età moderna (1542-1730). La Tabula chronologica inquisitorum di Domenico Francesco Muzio O.P. (†1730), Milano, Wolters Kluwer - Cedam

Errera A., 2000: Processus in causa fidei. L'evoluzione dei manuali inquisitoriali nei secoli XVI-XVIII e il manuale inedito di un inquisitore perugino, Milano, Monduzzi

Errera A., 2018: La procedura inquisitoriale tra predicazione e diritto: la fase della inquisitio generalis, in L. Gaffuri, R. M. Parrinello (eds.), Verbum et ius. Predicazione e sistemi giuridici nell'Occidente medievale, Firenze, Firenze University Press, pp. 175-196

Eymerich N., Peña F., 1587: Directorium inquisitorum fratris Nicolai Eymerici ordinis Praedicatorum cum commentariis Francisci Pegñae [...], Romae, In Aedibus Populi Romani. Apud Georgium Ferrarium 
Ferrilli S., Cino da Pistoia, Francesco da Barberino e l'astrologia giudiziaria: tra poesia, politica e cultura giuridica, in F. Meier, E. Zanin (eds.), Poesia e diritto nel XIII e XIV secolo, Ravenna, Longo, pp. 105-124

Foucault M., 1975: Surveiller et punir. Naissance de la prison, Paris, Gallimard

Foucault M., 2011: L'emergenza delle prigioni. Interventi su carcere, diritto e controllo, Firenze, La Casa Usher

Franciscus de Pitigianis OFM, 1617: Practica criminalis canonica, Venetiis, Apud Iohannem Baptistam Ciortum

Fugazza E., 2017: Pavia, 1249. Publica fama e culpa nel processo contro i custodi del carcere, in "Italian Review of Legal History", 2, pp. 1-15

Gallo E., Ruggiero V., 1983: I/ carcere in Europa. Trattamento e risocializzazione, recupero e annientamento, modelli architettonici e pedagogici nella "galera d'Europa", Verona, Bertani

Garlati L., 2015: Miti inquisitori: la confessione tra ricerca della verità e 'garanzie processuali', in L. Luparia, L. Marafioti (eds.), Confessione, liturgie della verità e macchine sanzionatorie, Torino, Giappichelli, pp. 69-93

Garlati L., 2016: Per una storia del processo penale: le Pratiche criminali, in "Rivista di Storia del Diritto Italiano", 89, pp. 71-109

Garlati L., 2017: Sepolti vivi. Il carcere al tempo delle Pratiche criminali: riti antichi per funzioni nuove, in "Diritto Penale Contemporaneo", 4, pp. 12-27

Gazzini M., 2017: Storie di vita e malavita. Criminali, poveri e altri miserabili nelle carceri di Milano alla fine del medioevo, Firenze, Firenze University Press

Geltner G., 2012: La prigione medievale. Una storia sociale, Roma, Viella

Gigliotti V., 2018: Sulle origini dei rapporti tra ordinamento secolare e ordinamento religioso nella storia giuridica occidentale, in "Rivista di Storia del Diritto Italiano", 91, pp. 305-351

Grossi P., 2013: Scritti canonistici, Milano, Giuffrè

Heering J. P., 2004: Hugo Grotius as Apologist for the Christian Religion. A Study of His Work De veritate religionis christianae (1640), Leiden-Boston, Brill

Hieronymus Magonius, 1605: Decisiones Lucenses, in Id., Decisiones causarum tam Rotae florentinae quam Rotae lucensis, Venetiis, Apus Sessas

Hippolytus de Marsiliis, 1551: Averolda domini Hippolyti de Marsiliis bononiensis [...] elegans ac admodum accurata criminalium practica, Ludguni

lacobus Menochius, 1576: De arbitrariis iudicum quaestionibus et causis libri duo, Francofurti ad Moenum, Apud Petrum Fabricium

Iacobus Simancae, 1584: De catholicis institutionibus, in Tractatus Universi luris, $\mathrm{XI} / 2$, Venetiis, Apud Ziletum

Ignatius Lopez de Salcedo, 1666: Practica criminalis canonica, Moguntiae 
Iohannes Andreae, 1581: In Sextum decretalium librum Novella commentaria, Venetiis, Apud Franciscum Franciscium

Iohannes Baptista de Thoro, 1655: Codex casuum selectorum rerum iudicatarum, criminalium, civilium et mixtorum, Neapoli, Ex Regia Typographia Egidii Longhi

Iohannes Bernardus Díaz de Luco, 1614: Practica criminalis canonica, Venetiis, Apud Ioannem Guerilium

Isotton R., 2006: Crimen in itinere. Profili della disciplina del tentativo dal diritto comune alle codificazioni penali, Napoli, Jovene

Isotton R., 2012: Brevi considerazioni in tema di 'delitti di evasione' nel codice Rocco, in Id., Tra autorità e libertà. Saggi di storia delle codificazioni penali, Torino, Giappichelli, pp. 167-191

Iulius Clarus, 1574: Liber Quintus, Venetiis, Expensis Ioannis Antonii de Antoniis librarii mediolanensis

Jeffery R., 2006: Hugo Grotius in International Thought, London, Palgrave Macmillan

Lagioia V., 2017: «Indicibili delitti». Francesco Aretino, teologo e confessore del granduca Ferdinando I, in F. Alfieri, V. Lagioia (eds.), Infami macchie. Sessualità maschili e indisciplina in età moderna, Roma, Viella, pp. 87-110

Lavenia V., 2010: Peña, Francisco, in A. Prosperi, V. Lavenia, J. Tedeschi (eds.), Dizionario Storico dell'Inquisizione, Pisa, Edizioni della Normale, pp. 1186-1189

Lepsius S., 2013: Bartolo da Sassoferrato, in I. Birocchi, E. Cortese, A. Mattone, M. N. Miletti (eds.), Dizionario Biografico dei Giuristi Italiani (XII-XX secolo), Bologna, II Mulino, pp. 177-180

Liber Sextus, 1582: Liber Sextus decretalium Bonifacii papae VIII, suae integritati una cum Clementinis et Extravagantibus, earumque glossis restitutus, Romae, In aedibus Populi Romani

Liotta F., 2013: Guido da Baisio (Abaisius, Baiso, Baixio) detto l'Arcidiacono, in I. Birocchi, E. Cortese, A. Mattone, M. N. Miletti (eds.), Dizionario Biografico dei Giuristi Italiani (XII-XX secolo), Bologna, II Mulino, pp. 1092-1093

Lucchesi M., 2018: «Satis vulgaria sunt apud praedicatores». Motivi di riflessione e circolazione di idee in tema di gioco tra giuristi canonisti e frati predicatori (secolo XV), in L. Gaffuri, R. M. Parrinello (eds.), Verbum et ius. Predicazione e sistemi giuridici nell'Occidente medievale, Firenze, Firenze University Press, pp. 271-286

Ludovicus a Peguera, 1608: Decisiones aureae [...] ex variis sacri regii consilii Cathaloniae conclusionibus summo studio, iudicioque accuratissimo collectae, Venetiis, Apud lacobum Antonium Somaschum

Ludovicus Carerius, 1562: Practica causarum criminalium domini Ludovici Carerii rheginensis, Lugduni, Apud Gulielmum Rovillium 
Ludwig Jansen K., 2018: Peace and Penance in Late Medieval Italy, Princeton, Princeton University Press

Maffei P., 2013a: Cino Sinibuldi da Pistoia, in I. Birocchi, E. Cortese, A. Mattone, M. N. Miletti (eds.), Dizionario Biografico dei Giuristi Italiani (XII-XX secolo), Bologna, II Mulino, pp. 543-546

Maffei P., 2013b: Gambiglioni, Angelo, in I. Birocchi, E. Cortese, A. Mattone, M. N. Miletti (eds.), Dizionario Biografico dei Giuristi Italiani (XII-XX secolo), Bologna, II Mulino, pp. 939-941

Maffei P., 2020: Antelmi, Bonifacio (Vitalini, Bonifacio), in Dizionario Biografico degli Italiani, 99, Roma, Istituto della Enciclopedia Italiana, p. 738

Malavasi S., 2010: Carerio, Ludovico, in A. Prosperi, V. Lavenia, J. Tedeschi (eds.), Dizionario Storico dell'Inquisizione, Pisa, Edizioni della Normale, p. 273

Mancuso F., 2019: Tortura, confessione e pena di morte: un tragico caso di violenza sessuale minorile deciso dalla Rota di Lucca nel XVI secolo, in "Italian Review of Legal History", 5, pp. 1-37

Marchetti P., 1994: Testis contra se. L'imputato come fonte di prova nel processo penale dell'età moderna, Milano, Giuffrè

Martyn G., 2016: Matthaeus, in S. Dauchy, G. Martyn, A. Musson, H. Pihlajamäki, A. Wijffels (eds.), The Formation and Transmission of Western Legal Culture. 150 Books that Made the Law in the Age of Printing, Cham, Springer, pp. 205208

Massetto G. P., Parini, S., 2013: Claro, Giulio, in I. Birocchi, E. Cortese, A. Mattone, M. N. Miletti (eds.), Dizionario Biografico dei Giuristi Italiani (XII-XX secolo), Bologna, II Mulino, pp. 552-555

Massetto G.P., 2017: Scritti di storia giuridica, Milano, Giuffrè

Mausen Y., 2012: Accusation et dénonciation: au sujet de l'éthique de l'action pénal, in M. Schmoeckel, O. Condorelli, P. Roumy (eds.), Der Einfluss der Kanonistik auf die Europäische Rechtskultur. Bd. 3. Straf- und Strafprozessrecht, Köln-Weimar-Wien, Böhlau, pp. 411-426

Mazzacane A., 2013: Farinacci, Prospero, in I. Birocchi, E. Cortese, A. Mattone, M. N. Miletti (eds.), Dizionario Biografico dei Giuristi Italiani (XII-XX secolo), Bologna, II Mulino, pp. 822-825

Meccarelli M., 1998: Arbitrium. Un aspetto sistematico degli ordinamenti giuridici in età di diritto comune, Milano, Giuffrè

Meccarelli M., 2009: Paradigmi dell'eccezione nella parabola della modernità penale. Una prospettiva storico-giuridica, in "Quaderni Storici", 131, pp. 493521

Meccarelli M., 2016: Pensare la legge nel tempo dell'autonomia del diritto. Esperienze medievali e moderne, in C. Storti (ed.), Le legalità e le crisi della 
legalità, Torino, Giappichelli, pp. 127-157

Meccarelli M., 2017: Giustizia e vendetta: la rappresaglia tra età medievale e moderna. Un quadro teorico, in G. Francesconi, L. Mannori (eds.), Pistoia violenta. Faide e conflitti sociali in una città italiana dall'età comunale allo Stato moderno, Pistoia, Società Pistoiese di Storia Patria, pp. 17-29

Melossi D., Pavarini, M., 2018: Carcere e fabbrica. Alle origini del sistema penitenziario, Bologna, II Mulino

Miletti M. N., 2015: Diritto e processo penale: storia di una dialettica tra antico e nuovo regime, in F. Danovi (ed.), Diritto e processo: rapporti e interferenze, Torino, Giappichelli, pp. 9-53

Monti A., 2003: ludicare tamquam deus. I modi della giustizia senatoria nel Ducato di Milano tra Cinque e Settecento, Milano, Giuffrè

Mühlegger F., 2007: Hugo Grotius. Ein christlicher Humanist in politischer Verantwortung, Berlin, De Gruyter

Nappo T., Noto P. (eds.), 2002: Magoni, Gerolamo, in Indice Biografico Italiano, München-London-New York-Paris, K. G. Saur, 3, ad vocem

Nellen H. J. M., 2015: Hugo Grotius. A Lifelong Struggle for Peace in Church and State. 1583-1645, Leiden-Boston, Brill

Neppi Modona G., 1973: Carcere e società civile, in R. Romano, C. Vivanti (eds), Storia d'Italia. V/2, Torino, Einaudi, pp. 1906-1998

Nobile Mattei G. A., 2018: I Responsa di Andrea Alciato. Osservazioni preliminare e prospettive di ricerca, in "Historia et ius", 14, pp. 1-32

Nobile Mattei G. A., 2019: Prospettive moderne per una teoria della pena. Declinazioni della giustizia e causae puniendi tra XVI e XVII secolo, in "Quaderni Fiorentini", 48, pp. 183-220

Padoa Schioppa A., di Renzo Villata M. G. (eds.), 2002: Bibliotheca Senatus Mediolanensis. I libri giuridici di un Grande Tribunale d'ancien régime, Milano, Hoepli

Padoa Schioppa A., 2003: Italia ed Europa nella storia del diritto, Bologna, II Mulino

Padoa Schioppa A., 2020: Stato e Chiesa in Europa in prospettiva storica: uno sguardo di insieme, in "Rivista di Storia del Diritto Italiano", 93, pp. 7-45

Padovani A., 2013: Tartagni, Alessandro (Imola, 3 settembre 1423/1424? Bologna, 3 settembre 1477), in I. Birocchi, E. Cortese, A. Mattone, M. N. Miletti (eds.), Dizionario Biografico dei Giuristi Italiani (XII-XX secolo), Bologna, II Mulino, pp. 1942-1944

Padovani A., 2019: Tartagni, Alessandro, in Dizionario Biografico degli Italiani, 95, Roma, Istituto della Enciclopedia Italiana, ad vocem

Paglia V., 1980: La pietà dei carcerati. Confraternite e società a Roma nei secoli 
XVI-XVIII, Roma, Edizioni di Storia e Letteratura

Panormitanus, 1588: Nicolai Tudeschii catinensis siculi, Panormi archiepiscopi, vulgo abbatis Panormitani Commentaria in quartum, et quintum librum decretalium, Venetiis, Apud luntas

Passarella C., 2018: Fra gli "orrori d'una tomba mortifera": le prigioni veneziane tra diritto e letteratura, in "Italian Review of Legal History", 4, pp. 1-19

Pastore S., 2010: Simancas, Diego de, in A. Prosperi, V. Lavenia, J. Tedeschi (eds.), Dizionario Storico dell'Inquisizione, Pisa, Edizioni della Normale, pp. 1430-1431

Pedrini D., 2018: La fuga dal carcere in età moderna attraverso i documenti del tribunale vescovile di Jesi, in "Marca/Marche. Rivista di storia regionale", 11, pp. 203-215

Pennington K., 2019: Canonical Jurisprudence and Other Legal Systems in the Medieval and Early Modern Periods, in J. Miñambres (ed.), Diritto canonico e culture giuridiche nel centenario del Codex luris Canonici del 1917, Roma, Edizioni dell'Università della Santa Croce, pp. 109-118

Petit J. G., Faugeron C., Pierre M., 2002: Histoire des prisons en France (17892000), Toulouse, Privat

Petrus de Ancharano, 1583: Super Sexto decretalium acutissima Commentaria, Bononiae, Apud societatem typographiae bononiensis

Petrus Follerius, 1556: Practica criminalis domini Petri Follerii, Lugduni, Apud haeredes lacobi luntae

Petrus Follerius, 1561: Canonica criminalis praxis [...] Marcellina nuncupata, Venetiis, Ex officina Marci de Maria salernitani, bibliopola neapolitani

Pifferi M., 2019: Per giustizia e per salvezza. Qualche riflessione sulla polifunzionalità della pena tra medioevo ed età moderna, in "Quaderni di diritto e politica ecclesiastica", 27, pp. 3-19

Pignata M., 2013: De Vio, Tommaso, in I. Birocchi, E. Cortese, A. Mattone, M. N. Miletti (eds.), Dizionario Biografico dei Giuristi Italiani (XII-XX secolo), Bologna, II Mulino, pp. 725-726

Pihlajamäki H., Korpiola M., 2014: Medieval Canon Law. The Origins of Modern Criminal Law, in M. D. Dubber, T. Hörnle (eds.), The Oxford Handbook of Criminal Law, Oxford, Oxford University Press, pp. 201-224

Pollorsi S., 2015: Recta ratione ductus. I Prolegomena al De Criminibus di Anton Matthaeus, Pavia, Pavia University Press

Prosperus Farinacius, 1589: Variarum quaestionum, et communium opinionum criminalium, Venetiis, Apus lohannes Variscum, et Paganinum de Paganinis

Pseudo Vitalinus, 1578: Angeli Aretini de maleficiis tractatus, [...] cui tractatus Alberti de Gandino, necnon Bonifacii de Vitalinis [...] subiecimus, Venetiis, Apud Franciscum de Franciscis senensem 
Quaglioni D., 1991: Domenico da San Gimignano, in Dizionario Biografico degli Italiani, 40, Roma, Istituto della Enciclopedia Italiana, p. 666

Rosoni I., 1995: Quae singula non prosunt collecta iuvant. La teoria della prova indiziaria nell'età medievale e moderna, Milano, Giuffrè

Rossi G., 2001: "Del modo di deferire all'autorità de' dottori". Scienza giuridica e communis opinio doctorum nel pensiero di Giovanni Battista De Luca, in D. Maffei, I. Birocchi, M. Caravale, E. Conte, U. Petronio (eds.), A Ennio Cortese. III, Roma, II Cigno Galileo Galilei, pp. 176-203

Rossi G., 2012a: Bartolo da Sassoferrato, in P. Cappellini, M. Fioravanti, B. Sordi (eds.), Enciclopedia italiana di scienze, lettere ed arti. II contributo italiano alla storia del pensiero. Ottava appendice. Diritto, Roma, Istituto dell'Enciclopedia Italiana, pp. 51-54

Rossi G., 2012b: La forza del diritto: la communis opinio doctorum come argine all'arbitrium iudicis nel processo della prima età moderna, in A. Sciumè (ed.), II diritto come forza, la forza del diritto. Le fonti in azione nel diritto europeo tra medioevo ed età contemporanea, Torino, Giappichelli, pp. 33-61

Rossi G., 2013: La versatile scienza del giurista quattrocentesco: note di lettura sulla Repetitio in I. Si fugitivi (C. 6.1.3) di Bartolomeo Cipolla, in M. G. di Renzo Villata (ed.), Lavorando al cantiere del 'Dizionario Biografico dei Giuristi Italiani (XII-XX sec.)', Milano, Giuffré, pp. 97-143

Rossi M. C. (ed.), 2013: La religione dei prigionieri, Caselle di Sommacampagna, Cierre

Rusche G., Kirchheimer O., 1968: Punishment and Social Structure, New York, Russel \& Russel

Santalucia B., 1998: Diritto e processo penale nell'antica Roma, Milano, Giuffrè

Santangelo Cordani A., 2017: «La pura verità». Processi antiereticali e Inquisizione romana tra Cinque e Seicento, Milano, Giuffrè

Sarti N., 1980-1981: Appunti su carcere-custodia e carcere-pena nella dottrina civilistica dei secoli XII-XVI, in "Rivista di Storia del Diritto Italiano", 53-54, pp. 67-110

Sbriccoli M., 1974: Crimen lesae maiestatis. II problema del reato politico alle soglie della scienza penalistica moderna, Milano, Giuffrè

Sbriccoli M., 2009a: La storia, il diritto, la prigione. Appunti per una discussione sull'opera di Michel Foucault, in Id., Storia del diritto penale e della giustizia. Scritti editi e inediti (1972-2007), Milano, Giuffrè, pp. 1077-1094

Sbriccoli M., 2009b: La benda della giustizia. Iconografia, diritto e leggi penale dal medioevo all'età moderna, in Id., Storia del diritto penale e della giustizia. Scritti editi e inediti (1972-2007), Milano, Giuffrè, pp. 155-208

Sbriccoli M., Bettoni A. (eds.), 1993: Grandi tribunali e Rote nell'Italia di antico 
regime, Milano, Giuffrè

Schnapper B., 1973: Les peines arbitraires du XIIle au XVIIle siècle (doctrines savantes et usages français), in "Tijdschrift voor Rechtsgeschiedenis", 41, pp. 237-277

Schnapper B., 1974: Les peines arbitraires du XIIle au XVIIIe siècle (doctrines savantes et usages français), in "Tijdschrift voor Rechtsgeschiedenis", 42, pp. 81-112

Sinnema D., Moser C., Selderhuis H. J. (eds.), 2015: Acta ed Documenta Synodi Nationalis Dordrechtanae (1618-1619), Göttingen, Vandenhoeck \& Ruprecht

Statuta Mirandulae, 1386: Statuti della Terra del Comune della Mirandola e della Corte di Quarantola riformati nell'anno MCCCLXXXVI, Modena, Tipi di G. T. Vincenzi, 1885

Storti C., 2013: Alberico da Rosciate, in I. Birocchi, E. Cortese, A. Mattone, M. N. Miletti (eds.), Dizionario Biografico dei Giuristi Italiani (XII-XX secolo), Bologna, II Mulino, pp. 20-23

Thomas Aquinas, 1594: Secunda secundae partis Summae totius theologiae, Venetiis, Apud haeredem Hieronymi Scoti

Thomas Y., 2016: Fictio legis. La finzione romana e i suoi limiti medievali, Macerata, Quodlibet

Travaglia Cicirello T., 2018: La pena carceraria tra storia, legittimità e ricerca di alternative, Milano, Giuffrè

Treggiari F., 2019: Ubaldi, Baldo di Francesco degli, in Dizionario Biografico degli Italiani, 97, Roma Istituto della Enciclopedia Italiana, ad vocem

Valsecchi C., 2000: Un'auctoritas del primo Trecento. Oldrado da Ponte e i suoi consilia, Milano, Giuffrè

Valsecchi C., 2009: Menochio, Giacomo, in Dizionario Biografico degli Italiani, 73, Roma, Istituto della Enciclopedia Italiana, pp. 521-524

Valsecchi C., 2013a: Oldrado da Ponte, in Dizionario Biografico degli Italiani, 79, Roma, Istituto della Enciclopedia Italiana, pp. 191-194

Valsecchi C., 2013b: Oldrado da Ponte, in I. Birocchi, E. Cortese, A. Mattone, M. N. Miletti (eds.), Dizionario Biografico dei Giuristi Italiani (XII-XX secolo), Bologna, Il Mulino, pp. 1452-1454.

Valsecchi C., 2013c: Menochio, Jacopo, in I. Birocchi, E. Cortese, A. Mattone, M. N. Miletti (eds.), Dizionario Biografico dei Giuristi Italiani (XII-XX secolo), Bologna, II Mulino, pp. 1328-1330

Varalda E., 2016: II contributo di Innocento III alla formazione della cultura giuridica occidentale: in particolare in relazione al noto principio "rei publicae interest ne crimina remaneanti impunita", in "Vergentis", 3, pp. 145-169

Volumen, 1558: Volumen complectitur Novellas constitutiones lustiniani principis 
post repetitam Codicis praelectionem editas Authentica vulgo appellant; tres item posteriores libros Codicis; Feudorum seu beneficiorum duos; Constitutiones Friderici II Imperatoris; Extravagantes duas Henrici VII Imperatoris et tractatum de pace Constantiae, Lugdunum, Apud Hugonem a Porta et Antonium Vincentium

Umbertus Locatus, 1583: Praxis iudiciaria inquisitorum, Venetiis, Apud Damianum Zalterium

Williams I., 2019: Common Opinion in the Fourteenth Century: Before the Common Learning, Before the Inns of Court, in D. Ibbetson, N. Jones, N. Ramsay (eds.), English Legal History and its Sources. Essays in Honour of Sir John Baker, Cambridge, Cambridge University Press, pp. 300-317

Wijffels A. A., van Rhee C. H., Alvazzi del Frate P. (eds.), 2013: European Supreme Courts. A Portrait though History, London, Third Millenium Publishing

Zanchinus Ugolinus, Camillus Campegius O.P., 1579: De haereticis domini Zanchini Ugolini [...] cum locupletissimis additionibus et summariis reverendi patris fratris Camilli Campegii papiensis Ordinis Praedicatorum, Romae, In Aedibus Populi Romani 